\title{
Possessed properties in Ulwa
}

\author{
Andrew Koontz-Garboden \\ The University of Manchester \\ andrewkg@manchester.ac.uk
}

\author{
Itamar Francez \\ University of Chicago \\ ifrancez@uchicago.edu
}

December, 2009

\begin{abstract}
This paper explores an understudied and poorly understood phenomenon of morphological syncretism in which a morpheme otherwise used to mark the head of a possessive NP appears on words naming property concept (PC) states (states named by adjectives in languages with that lexical category; Dixon 1982) in predicative and attributive contexts. This phenomenon is found across a variety of unrelated languages. We examine its manifestation in Ulwa, an endangered Misumalpan language of Nicaragua, where diachronic evidence clearly shows that a single affix is involved. We propose an explanation for the syncretism based on an explicit syntactic and semantic analysis of the relevant constructions. On the proposed explanation, the syncretism arises out of a combination of semantic and morphosyntactic facts of Ulwa grammar. Specifically, we propose that the Ulwa pattern exemplifies a possessive strategy of predication. Intuitively, this strategy is a manifestation in grammar of the idiomatic equivalence between the property of being $F$ and the property of having F-ness.
\end{abstract}

\section{Introduction}

It is by now generally recognized that compositional, model-theoretic semantic analysis can be fruitfully applied to so called functional elements, i.e. grammatical words or morphemes such as tense and aspect markers, relativizers, or plural morphology. For example, Dowty's (1979) analysis of the English progressive aspect involved assuming a progressive operator, realized as the progressive morpheme-ing. Assigning an explicit semantics to the progressive morphology allowed Dowty to analyze the semantic interaction of this morphology with verbs of different aspectual classes.

Contexts in which a single functional word or morpheme is used in multiple, seemingly unrelated environments, to which we refer as contexts of syncretism, form an interesting challenge for the application of compositional, model-theoretic semantic analysis to the functional domain. Consider, for example, the uses of the Spanish clitic se, illustrated in (1).

$$
\begin{aligned}
& \text { a. El vaso se rompió. } \\
& \text { the glass SE broke } \\
& \text { 'The glass broke.' (anticausative) } \\
& \text { b. Alex se lavó. } \\
& \text { Alex SE washed } \\
& \text { 'Alex washed himself.' (reflexive) } \\
& \text { c. Se golpearon el uno al otro. } \\
& \text { SE hit the one to.the other } \\
& \text { 'They hit one another.' (reciprocal) }
\end{aligned}
$$


d. Los rumores sobre el nuevo encarcelamiento se divulgaron por un periodista the rumors about the new inprisonment SE divulged by a journalist ajeno a TVE.

close to TVE

'The rumors about the imprisonment were divulged by a journalist close to the TVE.'

(passive; Mendikoetxea 1999:1683)

Given the different kinds of meanings generated by the $s e+\mathrm{V}$ construct in $(1 \mathrm{a}-\mathrm{d})$, these data immediately raise the question of the semantic contribution of $s e$. Do the different occurrences of the morpheme se express the same semantics, or are multiple denotations for the morpheme involved? If the latter, are the various meanings of the morpheme unrelated (homonymy) or are they interrelated in a way that makes them a natural class (for example, by sharing a single underspecified meaning). This question must be decided on a case-by-case basis. Some cases arguably call for an analysis in terms of monosemy (e.g., Murray 2008 on the reflexive/reciprocal syncretism, at least in English and Cheyenne), while others are clear cases of homonymy (English plural versus possessive $s$ ).

Beyond the urgency of deciding between monosemy, polysemy, or homonymy for a given syncretic pattern within a particular language, a deeper question about the nature of universal grammar arises when such a pattern occurs consistently across languages. For example, the reflexive/anticausative syncretism exhibited by Spanish in $(1 \mathrm{a}, \mathrm{b})$ above is well-known to be attested in many genetically unrelated languages (Haspelmath 1990; Klaiman 1991; Kemmer 1993). Assuming that typological variation is governed, at least to a large degree, by the same universal principles of grammar that shape the grammars of particular languages, the reoccurrence of such a pattern calls for a grammatical explanation. An analysis in terms of homonymy for a morpheme like Spanish se thus becomes highly implausible, as it begs the question why the same two functions are realized by morphemes of the same phonological shape in language after language. Instead, one is lead to search for a unified analysis of the reflexive and anticausative semantic categories that could motivate their identical marking. In the case of anticausativization and reflexivization, such an analysis has indeed been argued for by Chierchia (2004) and Koontz-Garboden (2009a), who reduce the semantics of anticausativization to the semantics of reflexivization. ${ }^{1}$ We believe such crosslinguistically robust cases of syncretism are often manifestations of deep grammatical generalizations. The detailed study of particular cases is therefore crucial for understanding the grammatical principles underlying these generalizations.

The possibility of fruitfully applying formal semantic analysis to patterns of syncretism has been only scarcely explored in the literature. This paper contributes to this agenda by exploring in detail a somewhat more exotic case of syncretism found in some form or another in a variety of less well-studied languages. The phenomenon is one whereby a single morpheme surfaces in two seemingly unrelated contexts: ${ }^{2}$

- Possessed nouns in a possessive NP.

\footnotetext{
${ }^{1}$ The idea that anticausativization might be reduced to reflexivization is an old one, going back at least to Lakoff (1971). The contribution of Chierchia (2004) and Koontz-Garboden (2009a) is to make this semantic intuition formally explicit, with Koontz-Garboden (2009a) showing that it generates a range of lexical semantic predictions (borne out by the data) that were previously undetectable by informal statements of this hypothesis.

${ }^{2}$ For simplicity, this paper assumes a morpheme-as-items approach to morphology, but nothing we have to say relies on this assumption. The analysis could easily be recast in a theory of morphology which makes no reference to morphemes.
} 
- Attributive and predicative uses of property concept (PC) words, by which we mean words naming concepts that are expressed by adjectives in languages with this category (Dixon 1982).

We concentrate on the occurrence of this pattern in Ulwa, an endangered Misumalpan language spoken by 350 adults on the Atlantic coast of Nicaragua. ${ }^{3}$ The pattern involves the morpheme $-k a$, and is illustrated in (2). ${ }^{4}$
a. Alberto pan-ka
Alberto stick-KA
'Alberto's stick'
b. Yang as-ki-na minisih-ka.
1 SING shirt-1 SING dirty-KA
'My shirt is dirty.'
c. Al adah-ka as tal-ikda.
man short-KA INDEF see-1SING.PAST
'I saw a short man.'

$(0405-829)$

(Green 2004:asna)

The data in (2a) show that $-k a$ marks the third person singular form of the possessive relation. The data in $(2 \mathrm{~b}, \mathrm{c})$, by contrast, show that $-k a$ also appears on words naming "property concept states" (Dixon 1982), words that are translated as adjectives in languages that have that lexical category, in both predicative (2b) and attributive (2c) uses. We refer to $-k a$ in examples like (2a) as possessive $k a$, and to $-k a$ as it occurs in (2b,c) as $P$ (roperty)C(oncept)-ka.

Evidence from diachrony, discussed in $\S 2$, shows unambiguously that this syncretic pattern in Misumalpan is not a case of accidental homophony between two distinct morphemes, but rather that a single morpheme is involved. Furthermore, the fact that shared marking in PC and possessive contexts is found in a number of genetically unrelated languages (as shown in §2.1), further indicates that this pattern should be grammatically motivated.

The main theoretical goal of this paper is to propose a synchronic explanation for this

\footnotetext{
${ }^{3}$ The orthography used in the Ulwa examples below is that adopted by the Ulwa Language Project, itself an adaptation of the Miskitu orthography devised by Moravian missionaries (Green 1999:33). The orthographic conventions are mostly straightforward and are discussed by Green (1999:33ff.). The less self-explanatory conventions are: (a) use of the circumflex above a vowel for contrastively long vowels, (b) $n g$ is used for the velar nasal, (c) $h$ following any of the sonorants $l, r, n, n g, m$ indicates that the sonorant is voiceless.

Glossing conventions throughout the paper are as follows: AUX, auxiliary; COP, copula; $-\mathrm{DA}-,-d a-$ verb class marker; DEF, definite article; DS, different subject switch reference marking; FUT, future tense; IMPER, imperative; INDEF, indefinite article; INF, infinitive; INTERR, interrogative marker; IRR, irrealis modality; IRREV, marker of irreverence; KA, the morpheme appearing on Ulwa words naming property concept states; LIG, the possessive marker in Tolai, as in Ross (1998); LINKER, the possessive marker in Hausa, as in Newman (2000); NEG, negative; NOM, nominative case; NON-NOM, non-nominative case; PA, $-p a$ - verb class marker; PAST, past tense; PL.EXCL, plural exclusive (of first person plural); PL.INCL, plural inclusive (of first person plural); PL, plural; POS, possessive in Huave (Kim 2008); PRES, present tense; PRFCT, perfect aspect; RAUPI, the Ulwa marker raupi (see Koontz-Garboden 2009c:476ff.), very roughly a marker of subjecthood; RF, reflexive in Huave (Kim 2008); REL, the possessive marker in Aleut, as in Malchukov (2000); SENT.KA, the sentential $\mathrm{ka}$ marker in Ulwa (see Koontz-Garboden In press); SING, singular; SS, same subject switch reference marking; TA, -ta- verb class marker; TOP, topic marker; WA, $-w a$ - verb class marker; $1,2,3,1$ st, 2 nd, 3rd person agreement; \langle\rangle , gloss inside angle brackets indicates glossed morpheme is an infix.

${ }^{4}$ Beyond these two contexts, a direct evidence evidential morpheme with the same phonological shape glossed here as sentential $k a$, and we believe unrelated to the uses discussed in this paper, appears in a number of other morphosyntactic contexts (Koontz-Garboden In press). We do not discuss these in this paper.
} 
pattern. To do so, an analysis of the syntax and semantics of the relevant constructions, i.e. of possession, attribution and predication in Ulwa, must first be given. Such an analysis would necessarily involve assumptions about the grammatical nature of $-k a$ itself. The occurrence of $-k a$ in all three contexts should then follow from the analysis and our proposal is indeed that a single possessive morpheme $-k a$ is involved in all three contexts. Of course, the occurrence of a possessive morpheme in possessive constructions is no mystery (assuming an explicit analysis of what it means to be a possessive morpheme is provided). What requires explanation is the occurrence of such a morpheme in attributive and predicative constructions involving PC words. The hypothesis we propose is that Ulwa grammar employs what we call a possessive strategy of predication, wherein certain lexemes which cannot enter a predication relation directly, can do so indirectly through the mediation of possessive semantics. At the core of this analysis is the idea that the intuitive equivalence between being in the extension of a predicate and having the property expressed by that predicate has grammatical manifestation. We argue that in Ulwa, for reasons that are made clear below, the only way of expressing that an object is in the extension of a predicate is asserting that the object stands in a possessive relation to the corresponding property. In $\S 1.1$, we present in outline form the key ideas behind our formal analysis, to be presented in full in $\S 4$ and $\S 5$.

\subsection{A synopsis of the analysis}

We begin with possessive NPs, which, following Barker (1995) we analyze as denoting descriptions. Possessive $-k a$ is analyzed as overtly realizing Barker's covert poss operator. Informally, possessive $-k a$ attaches to a common noun and returns the relation that holds of two individuals $a$ and $b$ iff $b$ bears the possessive relation to $a$ and $a$ is in the extension of the common noun. For example, a noun like $\operatorname{dog}$ is mapped to the relation that holds between two individuals $a, b$ iff $a$ possesses $b$ and $b$ is a dog.

Turning to PC lexemes, we first show that in Ulwa such lexemes are bound forms, i.e. require a host in order to participate in the syntactic, and hence also the semantic, combinatorial process. We refer to PC lexemes as roots throughout the paper. Descriptively, suffixation with $-k a$ is the canonical way of providing a host for such roots in Ulwa grammar. Omission of $-k a$ in predicative and attributive environments in elicitation results in unstable native speaker judgments, though naturally occurring cases of PC roots without $-k a$ in these contexts are attested, if rare. The cases we have found in our corpus generally follow a specific phonological generalization, discussed in $\$ 3.2$. Given that $\mathrm{PC}-k a$ and possessive $-k a$ are one and the same, our analysis must explain why $-k a$ (and not some other word or morpheme) acts as host for PC $-k a$ when a host is present. Bare uses of PC roots are amenable, at best, only to speculative analysis, given their marginal status in the grammar.

We propose that the pattern arises from the interaction between the semantics of PC lexemes themselves and the possessive semantics of $-k a$. We hypothesize that PC roots in Ulwa denote primitive properties in the property-theoretic sense (e.g., Chierchia and Turner 1988). We believe this is a natural assumption and similar ones have been made in the literature for other languages. ${ }^{5}$ By hypothesis then, the semantic type of $\mathrm{PC}$ roots is simple rather than functional, and they are therefore not predicable of entities. In order to achieve the semantic equivalent of predication with PC roots, some semantic change must be introduced. Since, as noted, there is

\footnotetext{
${ }^{5}$ Baker (2003) for example assumes that property denotation is a universal and defining feature of the adjective lexical category.
} 
$-k a$ suffixation on PC roots in predicative and attributive positions, it is natural and attractive to locate this change in the semantics of $-k a$, while retaining the essential possessive nature of this morpheme. This is be done by associating with $-k a$ another denotation, minimally different from the one discussed above. This second denotation applies to a property denoting argument (the PC root) and maps it to the (characteristic function of) the set of individuals who stand in the possessive relation to that property. Thus, the predicate denoted by PC words after $-k a$ suffixation can be thought of informally as "having the property denoted by the PC root".

On this analysis, the uniform semantic contribution of $-k a$ is to relate two individuals through the possessive relation. This contribution, however, is made in different ways in different contexts. The two denotations of $-k a$ we use are given in (3), where $\pi$ is the possessive relation, $p$ is the type of properties, and $\Pi$ is a metavariable over property-denoting expressions.

The denotations of $-k a$ :
a. $\quad \mathrm{ka}_{1}=\lambda P_{\langle e, t\rangle} \lambda x \lambda y[\pi(x, y) \& P(y)]$
b. $\quad \mathrm{ka}_{2}=\lambda \Pi_{p} \lambda x[\pi(x, \Pi)]$

In $§ 5.3$, we explain in more detail why associating these two denotations with $-k a$ does not amount to stipulating an ambiguity.

Thus, on this analysis, $-k a$ is a possessive morpheme, and the semantic motivation for its occurrence with PC roots is that it enables them to be predicated of individuals indirectly. What makes this possible is the intuitive equivalence, formalized as a meaning postulate in $\S 5.1$, between having a property and being in the extension of the corresponding predicate. For cases in which PC roots occur without $-k a$, we assume that an implicit type shifting operation applies to the root, the function of which is identical to Chierchia and Turner's $\cup$ operator, namely to map a property to the corresponding $\langle e, t\rangle$ predicate. Type shifting is therefore an alternative strategy to $-k a$ suffixation, which we refer to as the 'up'-strategy. In all cases where the 'up'-strategy can be used, so can $-k a$ suffixation. In other cases, however, the 'up'-strategy is not an option, since $-k a$ suffixation is necessitated by the phonological constraints mentioned earlier and discussed in $\S 3.2$.

The rest of this paper is structured as follows. $\S 2$ presents typological and diachronic evidence that possessive $-k a$ and $\mathrm{PC}-k a$ should be a given a unified analysis in terms of systematic grammatical principles. $\S 3$ gives an overview of the morphosyntax of possessive and PC $-k a$. $\S 4$ introduces our analysis of possession in Ulwa and $\S 5$ introduces the analysis of PC $-k a$ in attributional and predicative contexts, showing that the PC and possessive $-k a$ both contribute the possessive relation. We discuss some advantages afforded by this analysis in explaining a number of constructions in the language that are prima facie mysterious, particularly in $\S 6$, where we explore the facts surrounding a construction in which there are two rounds of $-k a$ suffixation and the use of PC lexemes with the predicate watah 'have'. We conclude by discussing the extent to which we believe this analysis can be extended to other languages with the same kind of syncretism and consequences of our proposals for the understanding of the semantics of possession. 


\section{Evidence against a homonymy analysis of Ulwa $-k a$}

\subsection{Typological evidence}

A first indication that the possessive/PC syncretism is not accidental comes from typology. If the pattern we are analyzing involved accidental homonymy, it would be expected not to occur in genetically unrelated languages. However, the relevant pattern does in fact recur in a number of the world's languages. ${ }^{6}$ The data in (4)-(8) illustrate this fact.

(4) Oroch (Tungusic; Avrorin and Lebedeva 1968:207 in Malchukov 2000:3)
a. nia d'uu-ni
man house-3SING
'man's house'
b. nia aja-ni
man good-3SING
'a good man'

(5) Aleut (Paleosiberian; Malchukov 2000:10)
a. hla-m ukina-a
boy-REL.SINGG knife-3SING
'(the) boy's knife' (Malchukov 2000:9)
b. hla-m angana-a
boy-REL.SING big-3SING
'a big boy'

(6) Tolai (Oceanic, Northwest Melanesia; Ross 1998:239)
a. a mapi na davai
ART leaf LIG tree
'leaves of a tree'
b. a mamat na vat
ART heavy LIG stone
'a heavy stone'

(7) Huave (Isolate, Oaxaca, Mexico; Kim 2008:203)
a. Xioki xa-chijk-iow xuwe xa-rramb-ey-an.
I and 1 POS-young.sibling-3PL very 1 POS-greedy-RF-PL
'I and my younger siblings are very greedy.'
b. Xiok xa-anch.
I 1POS-lazy
'I'm lazy'

\footnotetext{
${ }^{6}$ In the data below, careful observers will note that while some of the examples have possessive morphology in attributive constructions, others, like Ulwa, have it in predicative constructions, e.g., Huave in (7). Further study is needed in order to determine the broader typological landscape of the syncretism. While some languages with the syncretism such as Huave, Ulwa, and others (e.g., Mawé and Gavião, Tupian languages of Brazil; Meira 2006) do indeed have possessive morphology in predicative PC constructions, others, such as Mosetén and Hausa seem not to, having possessive morphology only in attributive constructions. For others, we are as yet unsure. The facts below are simply meant to show that the syncretism is not an isolated fact of Misumalpan, but they also do point to a rich typology which requires further study. The goal of this paper is simply to untangle the facts of Ulwa, with an eye toward the broader typology in future work.
} 


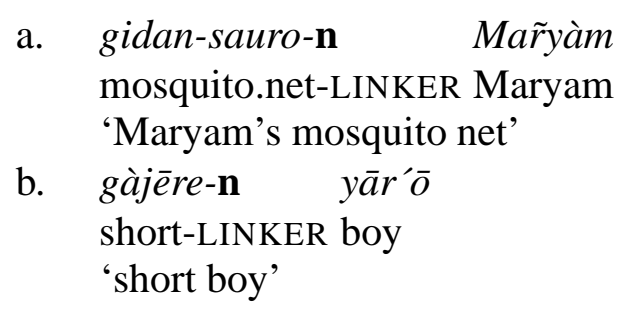

These data show that this pattern is part of the grammar of a variety of unrelated languages. Of course, it might still be the case that the syncretism is non-accidental generally, but an accident in Misumalpan. The facts from Misumalpan diachrony discussed in the next section offer a decisive argument against this position.

\subsection{Diachronic evidence}

\subsubsection{Some background on Ulwa and the Misumalpan family}

Ulwa is spoken by approximately 350 adults (Green 1999:18) in the village of Karawala, on Nicaragua's Atlantic coast and is an uncontroversial member of the Misumalpan family. The name of the family is formed by the concatenation of the the sub-family names of its members, Miskitu, Sumu, and Matagalpan. Ulwa belongs to the Sumu subfamily, which itself has two members, Northern Sumu, generally known by the name Mayangna and Southern Sumu, or Ulwa. Mayangna is considered to have three separate, but mutually comprehensible, dialects: Panamahka, Tawahka, and Tuahka (Benedicto and Hale 2000). By contrast, Ulwa is not mutually comprehensible with these dialects. The Sumu languages, in turn, are generally grouped together in a larger sub-family along with the now-extinct Matagalpan languages. It is only more distantly that these languages are presumed to be related to Miskitu (Campbell 1997:167; Benedicto and Hale 2000). These relationships are illustrated by the family tree in (3), taken from Benedicto and Hale (2000).

(9) Misumalpan family tree (Benedicto and Hale 2000:93) 


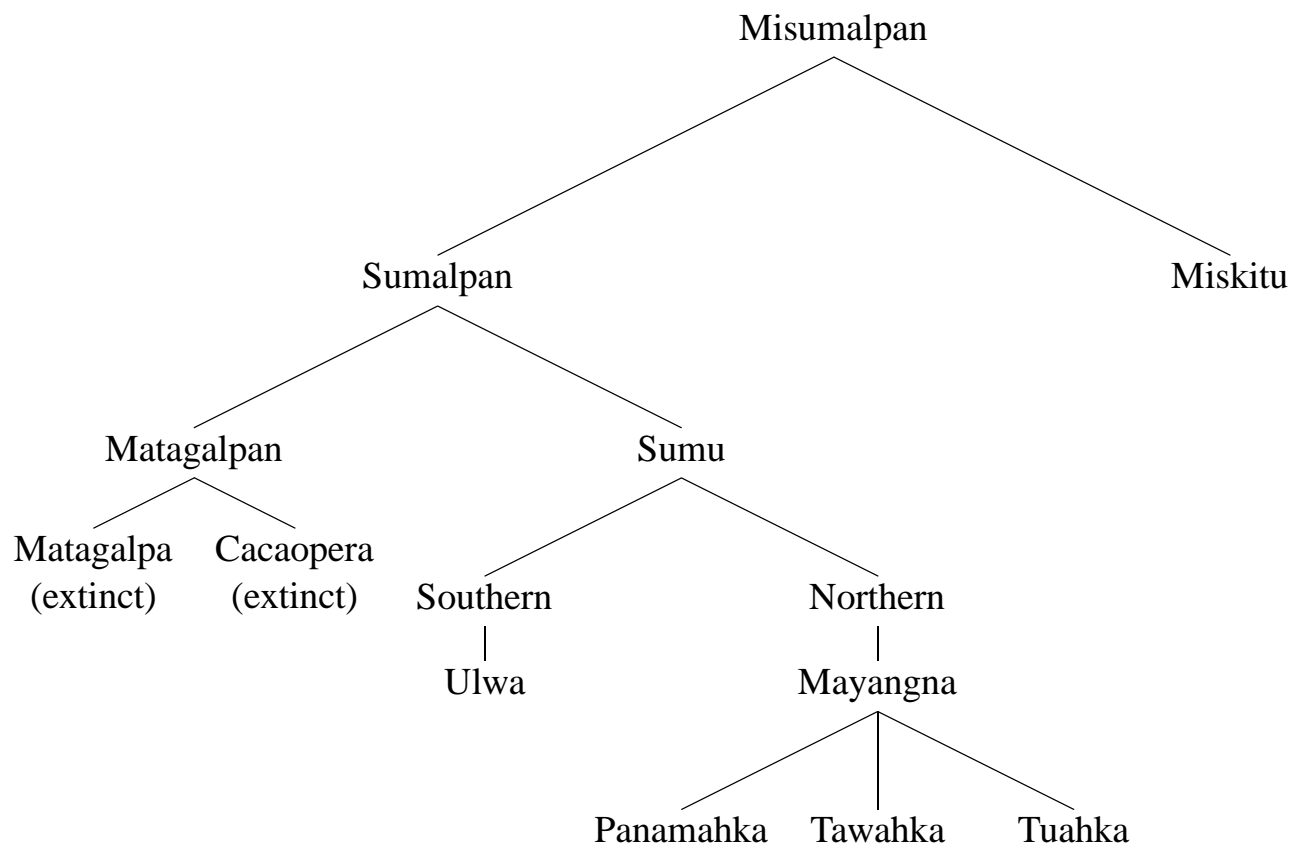

Ulwa, like Misumalpan more generally, has among its typological profile SOV word order, more head than dependent marking, nominative-accusative alignment, semantically and syntactically conditioned verb class morphology (Hale and Salamanca 2002; Hale and Keyser 2002; Koontz-Garboden 2009c), and subject switch-reference marking, which figures in a typologically marked causative construction that has attracted some attention (Young and Givón 1990; Hale 1991, 1997; Bittner 1999). The data reported on in the discussion that follows come from approximately fourteen months of the first author's fieldwork (2004-2009) and from Green's (1999) sketch grammar and dictionary, the latter which he has kindly made available to us in electronic form as an XML file (Green 2004). When citing data from this source, we cite the lexeme entry under which the example can be found. Data from the first author's fieldnotes are labelled according to the month and year in which the fieldwork was done (except for 0405, which was an eleven month fieldwork stint spanning 2004-2005), followed by the page number in the notes of that fieldtrip where the data can be found. With this as background, we now turn to some facts of diachrony showing the possessive/PC syncretism to be non-accidental in Ulwa.

\subsubsection{Property concept and possessive marking in Sumu}

The possessive/PC syncretism is found in Misumalpan not only in Ulwa, but also in its sister language Mayangna (Norwood 1997; Benedicto and Hale 2000), as illustrated in the table in (10).

(10) NP and PC suffixes in Ulwa and Mayangna (Benedicto and Hale 2000:98,100)

\begin{tabular}{lll} 
& 3sing poss & PC words \\
\hline \hline Ulwa & $-\mathrm{ka}$ & $-\mathrm{ka}$ \\
Mayangna & $-\mathrm{ni}$ & $-\mathrm{ni}$
\end{tabular}

The phonological shape of the suffix, $-n i$, is completely different from that of its Ulwa counterpart, $-k a$, yet both languages show the same kind of possessive/PC syncretism. We believe 
this situation arose out of a complicated, yet systematic shift in Misumalpan person/number morphology. According to Benedicto and Hale (2000), Mayangna underwent a "'person shift' ... according to which Northern Sumu [=Mayangna] third person morphology corresponds to Ulwa first person inclusive morphology, replacing the original Misumalpan ... third person morphology" (Benedicto and Hale 2000:98). More specifically, their claim is that the Ulwa nominal possessive paradigm, laid out in (11), represents the Proto-Misumalpan system.

\begin{tabular}{llllll}
\multicolumn{6}{c}{ Ulwa (and Proto-Misumalpan) nominal possessive paradigm (Green 1999:78) } \\
\hline \hline 1SING & - ki & 1PL.EXCL & -ki-na & 1PL.INCL & -ni \\
2SING & - ma & 2PL & -ma-na & & \\
3SING & - -ka & 3PL & -ka-na & &
\end{tabular}

When Ulwa and Mayangna split off from Proto-Misumalpan, while the person/number marking remained intact in Ulwa, in Mayangna there was a wide-spread shift, such that the morphology that in Proto-Misumalpan (and still in Ulwa) marks first person inclusive came to mark third person singular (with impersonal uses of first plural inclusive presumably the motivating force behind the shift). As Benedicto and Hale (2000) observe, this shift took place not only in the possessive paradigm, but also in the verbal morphology of the language. As a consequence of this shift, then, there is a systematic correspondence throughout the possessive (12) and the various verb-class (13)-(16) morphological paradigms between Ulwa first inclusive morphology and Mayangna third singular. ${ }^{7}$

(12) Ulwa first inclusive=Mayangna third singular (Benedicto and Hale 2000:98)

\begin{tabular}{lll}
\multicolumn{2}{c}{ Ulwa } & \multicolumn{2}{c}{ Mayangna } \\
\hline \hline 3SING & & \\
\hline 'hand' & ting-ka & ting-ni \\
'house' & û-ka & û-ni \\
'vulture' & kus-ka-ma & kus-ni-ma \\
1INCL & & \\
\hline 'hand' & ting-ni & mâ ting-ki \\
'house' & û-ni & mâ û-ki \\
'vulture' & kus-ni-ma & mâ kus-ki-ma \\
-ra- class verbs (Benedicto and Hale 2000:99) \\
\multicolumn{3}{c}{ Ulwa Mayangna } \\
\hline \hline 3SING \\
\hline 'run' îrai \\
1INCL \\
'run' $\quad$ yak-îri
\end{tabular}

\footnotetext{
${ }^{7}$ Benedicto and Hale (2000:99) divide verbs into morphological classes according to whether they are "intransitive" or "transitive." As an anonymous reviewer notes, this oversimplifies the situation, since some of these classes allow both transitive and intransitive verbs, as discussed for Ulwa by Koontz-Garboden (2009c). The names for the verb classes below are the names given to the Ulwa classes by Green (1999:Chapter 7). For a description of the Mayangna verb classes see Norwood (1997:Chapter 5).
} 
$-d a-$ class verbs (Benedicto and Hale 2000:99)

\begin{tabular}{lll} 
& Ulwa & Mayangna \\
\hline \hline 3SING & & \\
\hline 'play' & isdai & yak-isi \\
1INCL & & \\
\hline 'play' & yak-isdai & mâ isdi
\end{tabular}

$-w a-$ class verbs (Benedicto and Hale 2000:99)

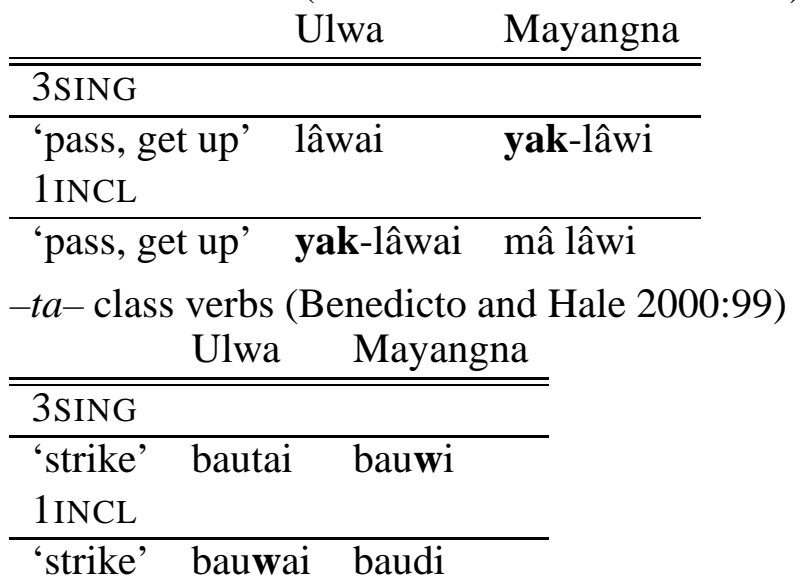

The observation, then, is that the Proto-Misumalpan 1inc. $\rightarrow$ Mayangna 3sing shift is a general feature of Misumalpan diachrony that caused the third singular possessive marker to shift from $-k a$ in Proto-Misumalpan to $-n i$ in Mayangna. Crucially, when $-n i$ shifted to marking the third singular NP in Mayangna, PC marking followed, so that-ni became the marker not only of third singular NP, but also the PC marker. That -ni appears on words naming PC states in Mayangna is entirely uncontroversial in the grammatical description of the language, as evidenced by the following statement in Norwood (1997) and by the illustrative data in (17).

Los adjetivos están compuestos de una raíz y una terminación, que es -ni.

'Adjectives [in Mayangna] are composed of a root and an ending, which is -ni.'

(Norwood 1997:65, translation ours)

(17) sâ-ni 'black'; puih-ni 'lukewarm'; ing-ni 'light'; sapah-ni 'bitter'; tihi-ni 'heavy'; nuh$n i$ 'big' (Norwood 1997:66-67)

These facts show that at least at the time of Proto-Misumalpan, a single morpheme was used in both PC marking and third singular NP marking. To assume otherwise is to claim that the possessive/PC syncretism came about as the result of completely independent accidental shifts in each individual daughter language, which is highly unlikely. We conclude that, at least in Proto-Misumalpan, a single suffix served for PC marking and possessive marking. The shift in phonological shape in Mayangna therefore naturally affected both contexts.

We take the data discussed in this section to establish that the possession/PC $-k a$ syncretism in Ulwa (and its reflex in Mayangna) is not accidental. The rest of this paper is devoted to developing an explanation for this syncretism rooted in the morphosyntax and semantics of the $-k a$ suffix. Our analysis is developed over the next three sections. The next section lays out the morphosyntactic facts which form the basis for the semantic analysis presented in $\S 4$ and $\S 5$. 


\section{The morphosyntax of possession and $\mathrm{PC}$ predication in Ulwa}

\subsection{The morphosyntax of Ulwa possessives}

As a starting point, we assume a fairly straightforward syntax for the Ulwa NP, with the possessor NP as the specifier of the NP projected by the possessed noun, marked with possessive morphology that agrees in person and number with the possessor. The full possessive morphology paradigm is given in (18).

(18) Nominal possessive paradigm (Green 1999:78)

$\begin{array}{llll}\text { 1SING } & -\mathrm{ki} & \text { 1PL.EXCL } & \text {-ki-na } \\ \text { 2SING } & -\mathrm{ma} & \text { 2PL } & - \text { ma-na } \\ \text { 3SING } & -\mathrm{ka} & \text { 3PL } & \text {-ka-na } \\ & & \text { 1PL.INCL } & - \text { ni }\end{array}$

We view $-k a$ (and is other person/number kin) as an affix which does not project any syntactic structure. The structure we assume for a simple Ulwa possessive NP like (2a) is given in (19).

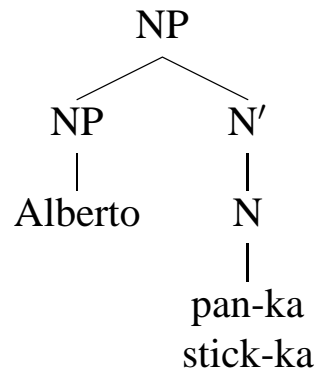

Alternatively, we could assume an Abneyan DP structure (Abney 1987) for the Ulwa NP, with $-k a$ as the D head. A DP syntax has been proposed for the related Misumalpan language Miskitu by Green (1992). One possible argument against adopting this for Ulwa is that this language does not show an article/possessor complementarity (Haspelmath 1999), contrary to the predictions of a DP analysis. In any case, while recognizing that the internal syntax of the Ulwa NP may well be more articulated, since this is not the primary focus of this paper, we assume only as much structure as is needed to lay out our semantic analysis, leaving more detailed work on Ulwa NP syntax for future research.

Possessor phrases can themselves have structure, for example when they contain quantifiers. We assume that possessors with quantifiers are constituents at surface structure. The structure assigned to possessive NPs with such possessors is as in (20). ${ }^{8}$

$$
\begin{aligned}
& \text { a. Bikiska balna luih tû-kana-ruh balna } \\
& \text { child PL all cow-POSS.3PL PL } \\
& \text { 'Every child's cows' }
\end{aligned}
$$

\footnotetext{
${ }^{8}$ We ignore here the syntactic status of the plural marker balna.
} 
b.

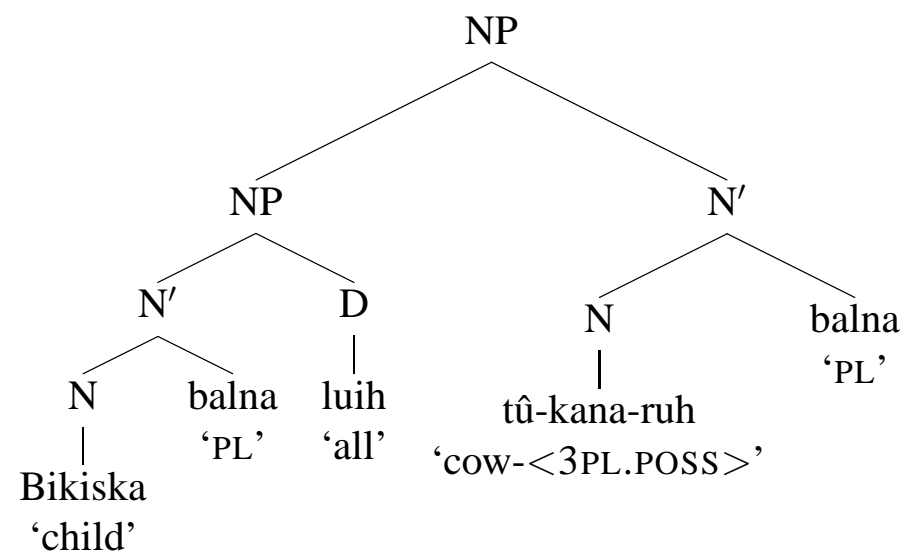

Note that in Ulwa the linearization of specifiers is not uniform. While determiners occur to the right of the nouns they specify, possessors appear to the left. We assume that the structures above are generated by the re-write rule in (21).

$$
\mathrm{NP} \rightarrow(\mathrm{NP}) \mathrm{N}^{\prime}(\mathrm{D})
$$

Finally, a clarification of the nature of affixation of possessive morphology with Ulwa nouns will facilitate discussion below. Contrary to what has been implied up to this point, affixation of possessive morphology is not always suffixation. Rather, Ulwa also has a rule of infixation of possessive morphology that has been somewhat celebrated in the phonological literature due to its sensitivity to prosodic structure (McCarthy and Prince 1998; Green 1999). The observation is that the process of infixation, exemplified in (22), should really be seen as suffixation to the leftmost iamb (a foot consisting of either a single heavy syllable, a light followed by a heavy, or two light syllables). The monomorphemic word sûlu 'dog' in (22a), for example, is composed of a heavy syllable followed by a light. Affixation of the possessive suffix, as shown in (22b), is, as a consequence, immediately following the first syllable, since it is heavy.

$$
\begin{array}{ll}
\text { a. } & \text { sûlu } \\
& \text { 'dog' } \\
\text { b. } & \text { sû-ki-lu } \\
& \operatorname{dog}-<1 \text { SING }> \\
& \text { 'my dog' }
\end{array}
$$

(Green 2004:aidanaka)

Many Ulwa words are simply composed of a single heavy syllable (23a), two light syllables (23b) or a light followed by a heavy (23c), so that affixation of the possessive morphology looks like garden variety suffixation. In more complicated cases, like (22) however, the force of the generalization is observed. ${ }^{9}$

$$
\begin{array}{ll}
\text { a. } & \hat{u}-k i \\
& \text { house-1 SING } \\
\text { 'my house' } \\
\text { b. } & a m i-k i \\
& \text { sister-1 SING } \\
\text { 'my sister' }
\end{array}
$$

(Green 2004:bil tisnaka)

\footnotetext{
${ }^{9}$ Green (1999:54ff.) shows the situation to be more complicated phonologically, as there are several instances where the generalization falsely predicts infixation. These complications are not relevant for current purposes.
} 


\author{
c. wahai-ki \\ brother-1 SING \\ 'my brother'
}

(0405-1036)

Having laid out both our assumptions and the basic facts regarding the morphosyntax of possessive NPs, we now turn our attention to the use of $-k a$ with PC roots.

\title{
3.2 The morphosyntactic function of $\mathbf{P C}-k a$
}

We refer to the expressions expressing property concepts in Ulwa as roots because they are morphologically bound and cannot occur as free-standing syntactic words. We view $-k a$ affixation as a lexical process the function of which is to form words out of such bound roots. The resulting words belong to the nominal syntactic category. ${ }^{10}$

As mentioned in $\S 1.1$, though $-k a$ affixation is generally the obligatory strategy for forming words out of PC roots in Ulwa, PC words in predicative and attributive position can sometimes occur without $-k a,{ }^{11}$ as in (24) and (25) respectively. ${ }^{12}$

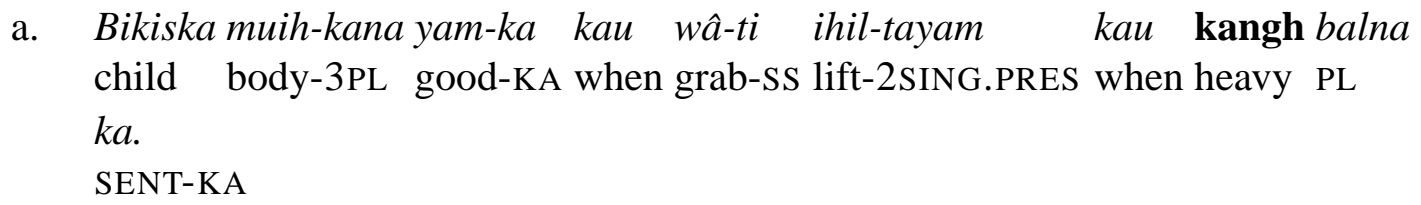

a. Bikiska muih-kana yam-ka kau wâ-ti ihil-tayam kau kangh balna child body-3PL good-KA when grab-SS lift-2SING.PRES when heavy PL $k a$.

SENT-KA

'When a child's body is healthy when you grab him/her and lift him/her up they are heavy.'
b. Yâkaas-ka-na ya wa-t-i tal-ing kau ahas dai. that shirt- $<3$ SING $>$ DEF grap-TA-SS see-1SING.PERF when rough PAST

\footnotetext{
${ }^{10}$ For a number of diagnostics showing PC words in $-k a$ to be nominal see Koontz-Garboden (2007:161-169).

${ }^{11}$ Another environment in which bare $\mathrm{PC}$ roots can, and more commonly do, occur is adjacent to a verb, as in (i).

(i) Was ya paras lautasa dai.

water the fast fall-TA-3SING.NEG PAST

'It didn't rain hard.'

(0405-495)

Such examples may involve, as a reviewer suggests, root-compounding. We leave these for future work.

${ }^{12} \mathrm{~A}$ reviewer perceptively asks how we know that $-k a$ in yabasikka 'afraid' in (25) is PC $-k a$, as suggested by our gloss, and not the direct evidence sentential $k a$ mentioned in fn. 4 . The answer is that, as shown by the meaning contrasts discussed in Koontz-Garboden (In press, 2009b), evidential $k a$ is never strictly obligatory with PC words. E.g., while (ia), consistent with the general meaning of evidential $k a$ requires direct evidence (e.g., having measured the item in question, as discussed by Koontz-Garboden In press), (ib) does not. The $-k a$ in (ib) cannot, therefore, be evidential $k a$, since the meaning of the sentence in (ib) is not consistent with the evidential meaning of evidential $k a$. Ergo, it must be PC $-k a$.
}

(i) Amang-ka ka.

enough-KA SENT-KA

'It is big enough.' (of a piece of wood, can only be said by person who measured it; 0405-747)

b. Amang-ka.

enough-KA

'It is big enough.' (of a piece of wood, can be said by someone who has not measured it, but only eye-balled it for adequacy of fit; 0405-747)

See Koontz-Garboden (In press) for additional examples and discussion. 
'That shirt, when I grabbed it and looked at it, it was rough/abrasive.' (0405-154)

Kuring mukul balna ya tulu-dai dî yabasik-ka.

canoe cylindrical PL DEF roll.over-3SING thing dangerous-KA

'When cylindrical canoes roll over, it is a dangerous thing.'

While these examples occurred naturally without $-k a$, in elicitation similar examples trigger unstable judgments from native speakers. In contrast, the equivalent sentences with $-k a$ are never problematic. This indicates that bare occurrences are a marginal part of native speakers' grammars. The generalizations we draw regarding them are therefore based on positive evidence, and must remain tentative. Based on a small corpus of 200 naturally occurring examples of PC words that we have compiled, the generalization that seems to emerge about when bare uses of PC roots are licensed is morphophonological. In the vast majority of cases in our corpus, where a bare root form is used, it is followed by a word that is at least bimoraic in phonological weight (CVCV, CVC, CVV, etc.). In the absence of such an environment, bare uses tend not to occur. The idea that bare PC roots cannot appear outside of this morphophonological environment is also supported by negative evidence, based on sentence final occurrences of PC words. Sentence finally, there is clearly no possibility of hosting the root, and native speaker intuitions in such cases are indeed robust (by contrast with intuitions about $-k a$ absence in contexts such as (24) and (25)). Examples such as (26a)-(29a) are consistently judged unacceptable, in contrast with their counterparts with $-k a$ in $(26 b)-(29 b)$.

$$
\begin{aligned}
& \text { a. *Baka-ki balna dut. } \\
& \text { child-1SING PL bad } \\
& \text { 'My children are bad.' } \\
& \text { b. Baka-ki balna dutka. } \\
& \text { child-1SING PL bad-KA } \\
& \text { 'My children are bad.' }
\end{aligned}
$$

$$
\begin{aligned}
& \text { a. *Tulh-ki ya yai. } \\
& \text { machete-1SING the sharp } \\
& \text { 'My machete is sharp.' }
\end{aligned}
$$

b. Tulh-ki ya yai-ka. machete-1SING the sharp-KA 'My machete is sharp.'

a. *Âka baka-ka âka suyu. this child-3SING this beautiful 'This child is beautiful.'

b. Âka baka-ka âka suyu-ka. this child-3SING this beautiful-KA 'This child is beautiful.'

$$
\begin{aligned}
& \text { a. *Baka ya saya. } \\
& \text { child the lazy } \\
& \text { 'The child is lazy.' } \\
& \text { b. Baka ya saya-ka. } \\
& \text { child the lazy-KA } \\
& \text { 'The child is lazy.' }
\end{aligned}
$$


We conclude from this that bare roots are not full-fledged free syntactic words, but can be used in their bare form provided that there is an adjacent word upon which they can be parasitic. In other words, the bare root has a clitic-like status and requires a word of a minimal phonological structure to host it. That Ulwa should have a constraint like this sits well with the language's aforementioned sensitivity to phonological weight in its prosodic structure, as evidenced by the facts of stress, infixation, and minimal word constraints (McCarthy and Prince 1998; Green 1999).

In addition to the bare root uses discussed above, there is also a small set of words that are translated as adjectives in English, hence PC words, and that never occur with $-k a$. These include umana 'old (inanimate)', almuk 'old/male (animate)', wana 'old/female (animate)' dûs 'brooding (of a hen)', and muhbul 'crazy.' These words clearly differ fundamentally from the Ulwa PC lexemes that are the focus of this paper, as $-k a$ affixation is both possible and the norm for the latter in most contexts, by contrast with this small exceptional set. We therefore treat these uniformly $-k a$-less PC words as a separate class, morphosyntactically and semantically, as discussed in fn. 15.

The question now arises why it should be $-k a$, rather than some other affix, that is invoked in the lexical rule turning roots into words. Our suggestion is that the reason is semantic. Specifically, we suggest that PC roots have denotations that make it impossible for them to enter into predication and attribution relations. Since such roots are required, in most contexts, to undergo a lexical process of affixation that turns them into words, it is natural for this lexical process to make use of an affix that, in combination with the denotation of the root, allows the resulting word to contribute the attribute/predicate required by the semantics of the construction. In $\S 5$ we show that, given that $-k a$ has the semantics of a possessive morpheme, it can fulfill this role.

As a final morphosyntactic consideration, the fact that it is only ever $-k a$, rather than any of its other person/number possessive morphology kin that suffixes to PC roots, even when the PC word is predicated of a first or second person, as in (30), also requires comment.

$$
\begin{aligned}
& \text { a. Adah-ka yang. } \\
& \text { short-KA 1SING } \\
& \text { 'I am short.' }
\end{aligned}
$$

b. Sang-ka man dah?

alive-KA 2SING still

'Are you still alive?'

(Green 2004:dah)

In Ulwa, there is agreement, as discussed in $\S 3.1$, within a possessive NP between the head and its specifier. There is no agreement between a non-verbal predicate and its head; the agreement appears instead outside of the non-verbal predicate in an auxiliary verb. This is true not only for PC words, but for all other nominal predicates, as illustrated by the garden variety nominal predicative constructions in (31). ${ }^{13}$

$$
\begin{aligned}
& \text { a. Yal as yang kau ... } \\
& \text { woman one } 1 \text { SING when }
\end{aligned}
$$

\footnotetext{
${ }^{13}$ The situation is slightly more complicated with posture verbs, which do have suppletive forms that agree in number. The point remains, however, that PC words behave exactly as expected with respect to person/number agreement if they are nominal predicates, as argued by Koontz-Garboden (2007:Chapter 6). With other nominal predicates there is no agreement on the non-verbal predicate itself, therefore there would be no expectation that there should be with predicative PC words either.
} 
b. Al as man.

man one 2 SING

'You are a man.'

(Mar08-1.9)

Given that PC words in $-k a$ are nouns, and that nouns in predicative position do not show agreement with their argument, it is unsurprising that there is no agreement for person/number on the predicative PC $-k a$ word. Furthermore, that it is the third person form of $-k a$, rather than some other form, which is used with PC roots is unsurprising, as third person commonly surfaces as the default form in non-agreeing contexts.

\section{An analysis of $-k a$ in possessives}

Our analysis of Ulwa possessives is based on Barker's (1995) theory of possessive descriptions. This theory in turn is based on the semantics of descriptions developed in the second chapter of Heim (1982). Heim's semantic theory relies heavily on rules manipulating a representational level of logical form, and we adopt similar rules. By logical form we intend a level of syntactic representation mediating surface structures and their translations in a formal language.

Barker's theory of possessive NPs is based on the following two features: (i) Possessive NPs denote descriptions, i.e. sets of individuals (type $\langle e, t\rangle$ ), on a par with definite and indefinite descriptions; and (ii) possession involves an underspecified binary relation $\pi$ which relates the entities described by the possessed NP to those described by the possessor NP. Thus, the logical form of a possessive NP on this theory is as in (32).

$$
\lambda x_{e}\left[\ldots \pi\left(\alpha_{e}, x\right) \& P(x)\right],
$$

where $P$ is a property contributed by the NP expressing the possessed

For example, a possessive description like John's table denotes the set of tables that are related by $\pi$ to John. Following Heim and Barker, we posit the rules in (33) for deriving logical forms from surface syntactic structures.

a. NP-adjoining: All argument NPs other than names and pronouns raise from their surface position and adjoin to the nearest $\mathrm{S}$. Possessive NPs other than names and pronouns raise from their surface position and adjoin to the nearest NP.

b. Quantifier construal: Every quantifier is adjoined as a leftmost constituent of S.

We assume the LF-formation rules of noun adjunction and quantifier construal are universal and thus work essentially the same in Ulwa as they do in English. Some examples of sentences and their logical forms are given in (34).

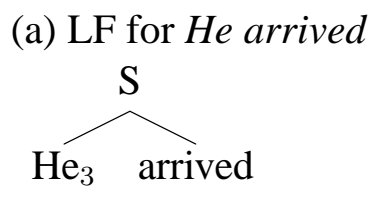

(b) LF for A man arrived =

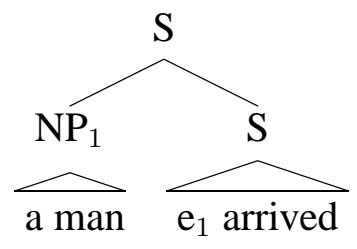


(c) LF for Every man arrived =

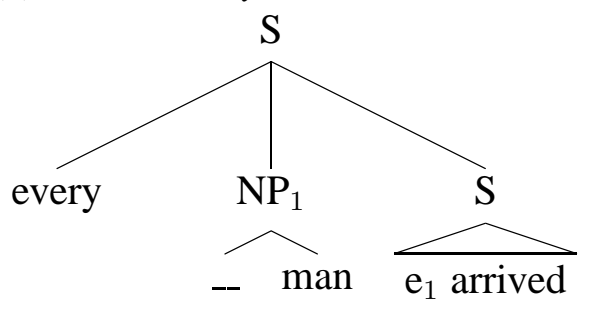

To exemplify Barker's analysis concretely, we reproduce in (35) his syntactic and semantic analysis of the NP John's table. The semantics takes the form of rules for translating LFs into a typed second order language with $\lambda$-abstraction and application. The language has an infinite set of individual, predicate and relation variables, as well as finite sets of individual, predicate and relation constants. Individual variables are written as $x_{0}, x_{1}, x_{2}$, etc. The predicate variables are $P, Q$, etc. and the relation variables are $R_{0}, R_{1}$, etc. Pronouns and traces are translated as individual variables, names as individual constants. Nouns are translated as $\langle e, t\rangle$-type properties. Determiners are interpreted as binary relations between sets. The notation $\llbracket$. $\rrbracket$ is used for the function associating expressions with their translations in the formal language. The modeltheoretic interpretation of these translations is entirely standard. We omit here the exact rules for LF interpretation assumed by Barker, but their workings are transparent in (35). Our own rules of LF interpretation are given in (36) below.

$$
\begin{aligned}
& \text { a. } \quad \text { S-Structure }=\mathrm{LF}= \\
& \text { DP } \\
& \text { John's } \\
& \text { b. } \llbracket \mathrm{DP}: \text { John's } \rrbracket=j \\
& \text { c. } \llbracket \mathrm{NP} \text { : table } \rrbracket=\lambda x[\operatorname{table}(x)] \\
& \text { d. } \llbracket \mathrm{D} \text { : poss } \rrbracket=\lambda P \lambda z \lambda y[\pi(z, y) \& P(y)] \\
& \text { e. } \quad \llbracket D^{\prime} \text { : table-poss } \rrbracket=\llbracket D^{\prime} \text { : poss } \rrbracket(\llbracket N P \text { : table } \rrbracket)= \\
& \lambda z \lambda y[\pi(z, y) \& \text { table }(y)] \\
& \text { f. } \quad \llbracket \text { DP: John's table } \rrbracket=\llbracket \text { D': table-poss } \rrbracket(\llbracket D: \text { John's } \rrbracket)= \\
& \lambda y[\pi(j, y) \& \text { table }(y)]
\end{aligned}
$$

Barker's analysis of English possessive descriptions relies on two assumptions about the interaction between morphosyntactic form and semantic interpretation. The first is that possessed nouns combine with an empty determiner poss, which introduces the possessive relation $\pi$. The second is that the English possessive formative 's is meaningless. We take no stance as to the plausibility of these assumptions for English. Ulwa has no marking on possessor nouns, and so the question of the potential semantic contribution of such marking does not arise for us. However, we claim that in Ulwa, possessive $-k a$ is the overt realization of the poss operator.

Our semantics for Ulwa possessive NPs similarly takes the form of rules for assigning meanings to LFs. Whenever possible, interpretation proceeds by function application. Otherwise, interpretation proceeds according to the rules in SEM1-SEM5 in (36), which are our 
counterparts to Barker's (1995:126) LF interpretation rules. ${ }^{14}$

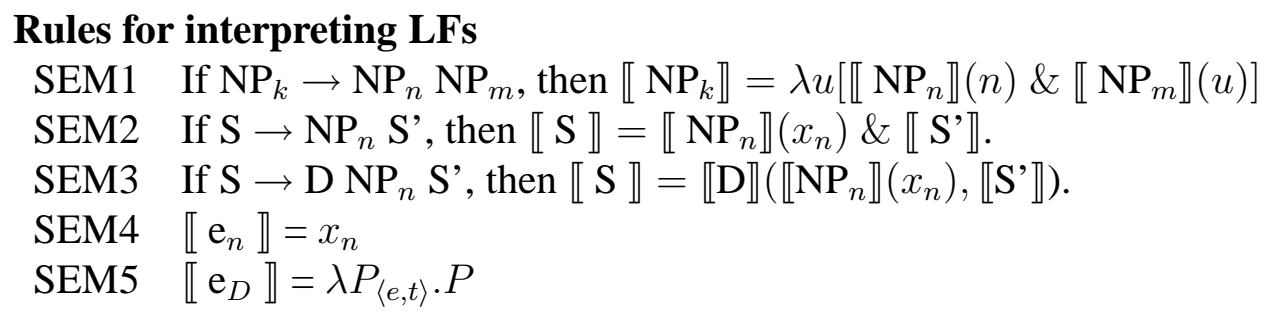

In order to exemplify how this semantics works, consider the Ulwa NP in (19) above. The LF for this sentence, given in (37), is identical to its surface structure.

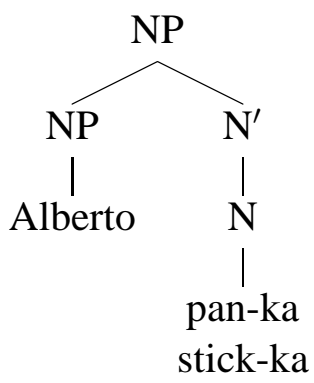

In order to interpret this LF, the meaning of NPs suffixed with $-k a$ must be specified. As mentioned, we analyze $-k a$ as the overt realization of Barker's poss operator, and we thus assign it the same meaning, as shown in (38).

$$
\llbracket-k a \rrbracket=\lambda P_{\langle e, t\rangle} \lambda x \lambda y[\pi(x, y) \& P(y)]
$$

The denotation of $-k a$ is a function $f: \wp(E) \rightarrow E \times E$, i.e. a function mapping properties to relations. This function takes a property and returns a set of pairs of individuals $\langle a, b\rangle$ such that $b$ is $P$ and stands in the underspecified $\pi$ relation to $a$. The derivation of the meaning of (37) is given in (39).

$$
\begin{array}{ll}
\text { a. } & \llbracket \text { NP: Alberto } \rrbracket=a \\
\text { b. } & \llbracket \mathrm{N}: \text { pan } \rrbracket=\lambda u[\operatorname{stick}(u)] \\
\text { c. } & \llbracket \text {-ka } \rrbracket=\lambda P_{\langle e, t\rangle} \lambda x \lambda y[\pi(x, y) \& P(y)] \\
\text { d. } & \llbracket \text { NP: pan-ka } \rrbracket=\llbracket-k a \rrbracket(\llbracket \text { N: pan } \rrbracket)= \\
& \lambda x \lambda y[\pi(x, y) \& \operatorname{stick}(y)] \\
\text { e. } & \llbracket \text { NP: Alberto pan-ka } \rrbracket= \\
& \llbracket \text { NP: pan-ka } \rrbracket(\llbracket \text { NP: Alberto } \rrbracket) \\
& =\lambda y[\pi(a, y) \& \operatorname{stick}(y)]
\end{array}
$$

Ulwa possessive NPs are thus interpreted as possessive descriptions on Barker's semantics.

As (40) shows, possessor NPs can themselves be definite or indefinite (or possessive) descriptions (40a), as well as quantificational (40b). The data in (41) show that the same state of affairs holds in Ulwa.

$$
\begin{aligned}
& \text { a. A man's table } \\
& \text { b. Every woman's table }
\end{aligned}
$$

\footnotetext{
${ }^{14}$ Our rules differ from Barker's only in being adapted to the non-DP syntax we assume for Ulwa NPs.
} 
a. Baka bât-ka

child fart-3SING

'A child's fart'

b. Bikiska balna luih tû-kana-ruh balna dai ka $\hat{\imath}$-wa-dida.

child PL all cow-POSS.3PL PL PAST SENT-KA die-WA-3PL.PAST

'Every child's cows died.'

(Mar08-7)

Within the Heimian set up assumed by Barker and adopted here, these data are handled by the LF operations of NP Adjunction and Quantifier Construal described above. Consider first the NP in (41a). This sentence on our analysis has the surface structure in (42).

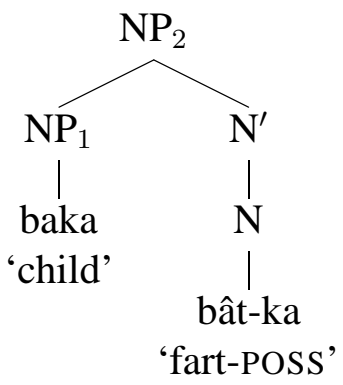

By NP adjunction, the NP baka 'child' is adjoined in LF as a sister of $\mathrm{NP}_{2}$, leaving behind a trace. The resulting LF is the one in (43).

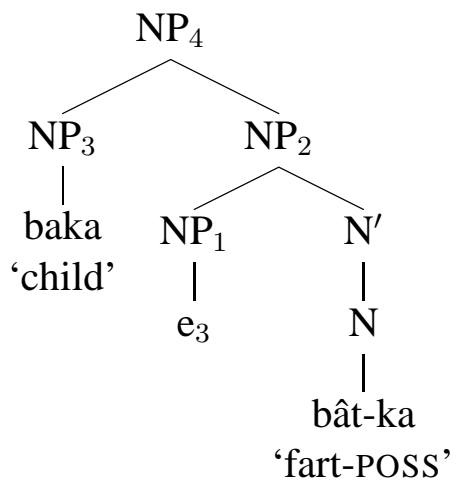

This LF is interpreted as in (44).

$$
\begin{array}{ll}
\text { a. } & \llbracket \mathrm{NP}_{1} \rrbracket=x_{3} \\
\text { b. } & \llbracket \mathrm{NP}_{2} \rrbracket=\lambda y\left[\pi\left(x_{3}, y\right) \& \operatorname{fart}(y)\right] \\
\text { c. } & \llbracket \mathrm{NP}_{3} \rrbracket=\lambda x[\operatorname{child}(x)] \\
\text { d. } & \llbracket \mathrm{NP}_{4} \rrbracket=\left(\text { by SEM1) } \lambda u\left[\operatorname{child}\left(x_{3}\right) \& \pi\left(x_{3}, u\right) \& \operatorname{fart}(u)\right]\right.
\end{array}
$$

The variable $x_{3}$ is free in (44d), and the denotation of the possessive $\mathrm{NP}_{4}$ cannot be determined until it is given a value. We assume following Heim (and Barker) that all free variables in descriptions are bound, in the absence of any overt binder, by existential closure at the clause level (cf. Heim's (1982) text formation rule).

The analysis of quantified possessors proceeds in a very similar fashion, except that the determiners of possessor NPs are adjoined to $\mathrm{S}$ at LF and construed as unselective binders. Thus, the LF of the Ulwa sentence in (41b) is as in (45). 


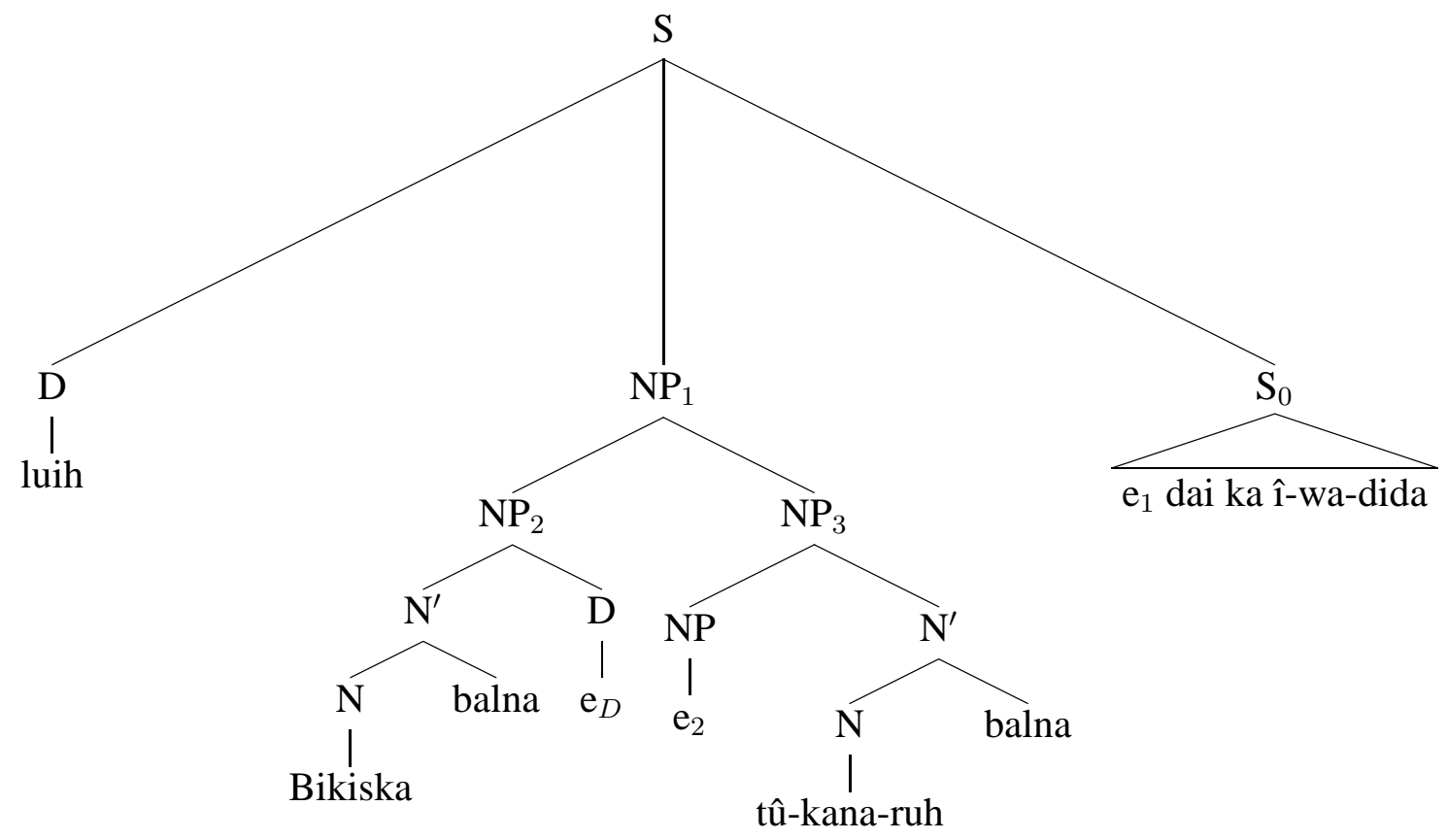

Determiners are interpreted as relations between sets of assignments (of individuals to variables) rather than sets of individuals. For example, the denotation of every (and of Ulwa luih) is given in (46). We use $p, q$ as variables of type $t$, and the the notation $[p]^{g}$ for the value of an expression of type $t$ relative to an assignment $g$.

$$
\llbracket \text { every } \rrbracket=\lambda p_{t} \lambda q_{t}\left[\left\{h:[p]^{h}=1\right\} \subseteq\left\{g:[q]^{g}=1\right\}\right]
$$

The interpretation of the LF in (45) is then as in (47). We omit reference to the LF rules involved in the derivation.

$$
\begin{array}{ll}
\text { a. } & \llbracket \mathrm{S}_{0} \rrbracket=\operatorname{died}\left(x_{1}\right) \\
\text { b. } & \llbracket \mathrm{NP}_{3} \rrbracket=\llbracket \mathrm{N}^{\prime} \rrbracket\left(\llbracket \mathrm{e}_{2} \rrbracket\right)=\lambda y\left[\pi\left(x_{2}, y\right) \& \operatorname{cows}(y)\right] \\
\text { c. } & \llbracket \mathrm{NP}_{2} \rrbracket=\llbracket \mathrm{e}_{D} \rrbracket\left(\llbracket \mathrm{N}^{\prime} \rrbracket\right)=\lambda x[\operatorname{children}(x)] \\
\text { d. } & \llbracket \mathrm{NP}_{1} \rrbracket=\lambda u\left[\llbracket \mathrm{NP}_{2} \rrbracket\left(x_{2}\right) \& \llbracket N P_{1} \rrbracket(u)=\lambda u\left[\operatorname{children}\left(x_{2}\right) \& \pi\left(x_{2}, u\right) \& \operatorname{cows}(u)\right]\right. \\
\text { e. } & \llbracket \mathrm{S} \rrbracket=\llbracket \mathrm{D} \rrbracket\left(\llbracket \mathrm{NP}_{1} \rrbracket\left(x_{1}\right), \llbracket \mathrm{S}_{0} \rrbracket\right)= \\
& \lambda p_{t} \lambda q_{t}\left[\left\{h:[p]^{h}=1\right\} \subseteq\left\{g:[q] t^{g}=1\right\}\right]\left(\operatorname{child}\left(x_{2}\right) \& \pi\left(x_{2}, x_{1}\right) \& \operatorname{cows}\left(x_{1}\right)\right) \\
& \left\{h:\left[\operatorname{dinildren}\left(x_{2}\right) \& \pi\left(x_{2}, x_{1}\right) \operatorname{cows}\left(x_{1}\right)\right]^{h}=1\right\} \subseteq\left\{g:\left[\operatorname{died}\left(x_{1}\right)\right]^{g}=1\right\}
\end{array}
$$

(47e) says that the sentence in (41b) is true iff every assignment function that assigns a child to $x_{2}$ and a cow to $x_{1}$ such that the child possesses the cow, is an assignment in which the cow dies. Such a semantics for quantified possessives gives rise to well known issues of individuation generally known as the proportion problem. These problems are however orthogonal to our main concern here. For extensive discussion of the proportion problem in relation to an unselective binding analysis of quantified possessors see Barker (1995). This concludes our application of Barker's theory of possessive descriptions to Ulwa possessive NPs. We now move on to discuss the use of $-k a$ in constructions involving PC words. 


\title{
$5-k a$ with PC roots
}

Recall that the use of $-k a$ with PC roots involves contexts of predication and attribution, as in (48) (repeated from (2) above).

\author{
a. Yang as-ki-na minisih-ka. \\ 1SING shirt-1SING dirty-KA \\ 'My shirt is dirty.' \\ b. Al adah-ka as tal-ikda. \\ man short-KA INDEF see-1SING.PAST \\ 'I saw a short man.'
}

(Green 2004:asna)

$(0405-438)$

The semantic contribution of a PC word with $-k a$ affixed to it should therefore be the same as the contribution of predictive and attributive adjectives in a language like English. For example, it seems natural to analyze minisih- $k a$ 'dirty' in (48a) as denoting a function that maps all dirty individuals to true and the rest to false. One option is of course to simply assign PC words with $-k a$ the correct denotation, ignoring their morphological structure. However, we have been arguing that there is a grammatical generalization to be made about why it is $-k a$ that figures in the derivation of PC words rather than some other affix. Recall that affixation is required to turn PC roots into free-standing syntactic words. We have established that $-k a$ contributes possessive semantics in combination with a possessed noun. Our claim is that $-k a$ contributes possessive semantics also in PC contexts, and that this semantics makes it the only affix in the inventory of Ulwa that can generate the right denotations for syntactically free-standing PC words.

Specifically, we hypothesize that PC roots themselves denote primitive properties, i.e. what in a language like English is denoted by forms derived by means of nominalization (words such as happiness or roundness). ${ }^{15}$ This idea is supported by examples where, given the right prosodic conditions, the bare root can be found, with a primitive property-type meaning, as with the data in (49).

$$
\begin{aligned}
& \text { Saya } y \hat{a} \quad \hat{\imath}-t-a i . \\
& \text { lazy 1SING.NON-NOM kill-TA-3SING } \\
& \text { 'Laziness is killing me.' }
\end{aligned}
$$

(Oct09-100)

The formalization of this hypothesis is discussed shortly below. Intuitively, a primitive property is the counterpart in the domain of individuals of a particular truth-functional predicate. Primitive properties, being simple individuals, cannot be predicated of anything. However, there are several ways in which they can be made to enter a predication relation. First, some systematic mapping from properties to the corresponding predicates (intuitively, the inverse of nominalization) could apply to a property, yielding the proper $\langle e, t\rangle$ predicate. Such a mapping could be contributed overtly by e.g. a copula or it could be effected by means of a covert typeshifting operation. Second, a (different) systematic mapping could map a property to the set of individuals that "have" it. Presumably, the set of individuals that have a property is exactly the extension of the predicate corresponding to that property, and so this set could be used as

\footnotetext{
${ }^{15}$ Those few PC words discussed in $\S 3.2$ that never take $-k a$, we simply assume are indeed lexicalized as $\langle e, t\rangle$ predicates, and thus there is never the need or possibility to invoke the possessive strategy of predication with them, since they are of the wrong type.
} 
a 'proxy' for the predicate. ${ }^{16}$ In other words, we are suggesting that some languages that do not have adjectives have instead lexemes denoting primitive properties. The grammars of such languages can involve a possessive strategy for imitating predication. In this strategy, a primitive property $p$ is mapped by the possessive relation to the predicate have $p$, a predicate which is postulated to have the same extension as the predicative counterpart of $p$. We analyze Ulwa as employing exactly this strategy, where $-k a$ contributes the possessive relation. ${ }^{17}$ Thus, our semantics for constructions involving PC roots in Ulwa rests on the two assumptions in (50).

a. $\quad \mathrm{PC}$ roots denote primitive properties.

b. $\quad-k a$ is associated with a second possessive denotation, closely related to the first, which relates a property and an individual by the possessive $\pi$ relation.

Henceforth we refer to primitive properties simply as properties. Informally, the meaning we assign to a word formed from a PC root by suffixing $-k a$ is the predicate have $p$, where $p$ is the property named by the root. For example, the meaning of minisih-ka is having the property of dirtiness. This meaning is a function that maps any individual to true iff that individual has the property of dirtiness, i.e. iff the individual is dirty.

\subsection{Some notions of property theory}

In principle, our semantics could most naturally be couched in Chierchia and Turner's (1988) property theoretic language $P T_{1}$. However, $P T_{1}$ is first order and involves a completely different type system than the one we have been assuming so far. Recasting our analysis of possessive NPs in this language would take up much space and most likely reduce readability. We therefore maintain the standard setup used so far, and add here only as much property theory as is required for our purposes.

\footnotetext{
${ }^{16}$ We note that the postulation that for some individual to be $P$ is for that individual to have the property $P$-ness, is very natural and is reflected in many languages, including, to a limited extent, English. Thus, the example in (i) has intuitively the logical form in (ii).

(i) Sandy has all the required properties.

(ii) $\forall P($ required $(P) \rightarrow P($ Sandy $))$

${ }^{17} \mathrm{~A}$ reviewer raises the excellent question of what our analysis implies for the Ulwa equivalents of subsective and modal adjectives (such as English alleged) if such exist. At present, we do not have the data to show whether and in what form such words exist in Ulwa, and we leave this for future research.

The same reviewer also raises the issue of the intensifier palka 'very', which can be used with verbs (ia), nouns (ib), and PC words (ic), but is never, so far as we (or the reviewer for Mayangna) are aware, used on its own predicatively.
}
a. Muih almukbalna ya kalsungh ahau-ka â-wa-naka 'Old people like very much to wear loose-fitting clothing.'
b. Tip top ya aidingka pal-ka ka.
Tip top the cryer very-KA SENT-KA
'Tip top [=name of a person] is a big cryer.'
c. Warau ala-naka ya dî dasi-ka pal-ka ka. orphan raise-3SING.INF the thing difficult-KA very-KA SENT-KA
'Raising an orphan is a very difficult thing.'

wal-dai pal-ka ka. person old PL the trousers loose-KA enter-WA-3SING.INF want-3PL very-KA SENT-KA

(Green 2004:ahauka)

(Mar06-13)

Determining the implications of the palka facts for our analysis requires a better understanding of Ulwa degree constructions. We are currently undertaking work aimed at achieving such an understanding, and hope to have something to say on this in the future. 
We add to our standard Montagovian type system another type $p$, a subtype of $e$, which is the type of properties. Once properties are added to our language, they can be arguments of predicates and, in principle, of the predicates of which they are individual correlates. It is well known that this situation can easily lead to the Russell paradox. ${ }^{18}$ Within a properly axiomatized property theory, it is possible to ensure that the resulting logic is consistent (see e.g. the discussion in Chierchia and Turner 1988). To circumvent this issue, which is largely tangential to our concerns here, we make the simplifying assumption that while all properties are individual correlates of predicates, not all predicates have individual correlates. In fact, all we require is that there are enough properties in the model to serve as denotations for Ulwa PC roots. The operator $\cup$ is a total function from $D_{p}$ into $D_{\langle e, t\rangle}$. The role of $\cup$ is to map properties to $\langle e, t\rangle$ functions. For completeness, we include also the operator ${ }^{\cap}$ mapping functions back into properties. Given our assumption that not all functions have individual correlates, $\cap$ denotes a partial function from $D_{\langle e, t\rangle}$ to $D_{p} .{ }^{19}$ The operators $\cup$ and $\cap$ obey the meaning postulate MP1, where $\wp$ is a metavariable for properties. Henceforth, we use English expressions in capitals, e.g. DIRTY, to refer to constants of type $p$ and $\Pi$ as a variable over properties.

MP1 For all $\wp \in D_{p}, \cap \cup \wp=\wp$

\subsection{Possession of properties and property instantiation}

The intuition that possession can achieve something equivalent to what is expressed in predication is captured by the postulate MP2, which says that an individual stands in the possessive relation $\pi$ to a property iff that individual is in the extension of the corresponding function $/\langle e, t\rangle$ predicate. We take the desirability of such a postulate to be quite uncontroversial.

MP2 For all $\wp \in D_{p}$ and for all $a \in D_{e}, \pi_{\langle e,\langle e, t\rangle\rangle}(a, \wp) \Leftrightarrow{ }^{\cup} \wp(a)=1$

(51) is then a corollary of MP2.

$$
\text { For all } \wp \in D_{p}, \cup_{\wp}=\lambda x_{e}[\pi(x, \wp)]
$$

Thus, for any entity and any property, the entity "has" the property if and only if the entity is in the extension of the property's corresponding predicate in $D_{\langle e, t\rangle}$.

A reviewer raises the interesting issue of the semantic underspecification of $\pi$ in possessive NPs, as opposed to the tightly fixed meaning we take it to have in the context of PC words. As is well know, the possessive relation $\pi$ in a possessive NP is radically underspecified and can be resolved to practically any binary relation whatsoever given enough context. However, our MP2 essentially abolishes this context sensitivity for $\pi$ when the possessee is a property, ensuring that 'having' a property is equivalent to instantiating it. As the reviewer points out, this makes a rather strong prediction about Ulwa, namely that a PC word in $-k a$ should never be able to express a predicate that holds of all and only those individuals who stand in some contextually determined relation to the property of dirtiness other than instantiation (say, the set of individuals who were assigned the (formidable) task of eradicating dirtiness). We do not have data confirming or refuting this prediction. Obtaining such data would undoubtedly

\footnotetext{
${ }^{18}$ To see this, imagine the predicate being a property that is not in the extension of its correlating predicate. Call this predicate $\rho$, and its individual correlate $\Re$. Now ask (yourself): does $\rho$ hold of $\Re$ ?

${ }^{19}$ Linguistically, this operator is relevant when dealing with nominalization, but Ulwa nominalization is beyond the scope of this paper.
} 
be difficult, as it requires constructing somewhat far fetched and abstract scenarios in which individuals bare relations to properties other than instantiating them. Certainly, we are aware of no such uses of $-k a$ with PC words in our corpus, and we would be surprised to find them at all.

Assuming that $\pi$ is indeed not context sensitive in construction with PC roots, one might ask why this is so. This amounts to asking what might motivate the postulate MP2. In principle, we take MP2 to be a semantic primitive. However, what seems to underlie it is the fact that instantiation is by far the relation most commonly encountered by humans between objects and properties. Semantically, it is worth stressing in this context that what we are suggesting here is not that, in construction with PC words, $\pi$ resolves to a predication operator. In our semantics, $\pi$ is in all cases a binary relation on the domain of individuals, whereas predication is function application/set membership.

\subsection{The semantics of Ulwa PC words}

As previously mentioned, we take Ulwa PC roots to denote properties. Affixation of $-k a$ to a $\mathrm{PC}$ root is a lexical process required to turn the root into a word that can then participate in syntactic combinations and thus freely contribute to the propositional content of a sentence. Semantically, its effect is to allow the property denoted by the PC root to function as a predicate. More precisely, suffixation with $-k a$ maps the property denoted by the root to a function characterizing the set of entities that "have" that property.

To achieve this, we assume that $-k a$ is associated with a second possessive denotation in addition to its denotation in possessive NPs. The two denotations are given in (52) (repeated from (3)).

The denotations of $-k a$ :

a. $\quad \mathrm{ka}_{1}=\lambda P_{\langle e, t\rangle} \lambda x \lambda y[\pi(x, y) \& P(y)]$

b. $\quad \mathrm{ka}_{2}=\lambda \Pi_{p} \lambda x[\pi(x, \Pi)]$

To illustrate how the meaning of PC words is derived using the denotation for $-k a$ in $(52 b)$, we provide an example derivation of the meaning of minisih-ka 'dirty' in (53).

$$
\llbracket \text { minisih-ka } \rrbracket=\mathrm{ka}_{2}(\llbracket \text { minisih } \rrbracket)=\lambda \Pi_{p} \lambda x[\pi(x, \Pi)](D I R T Y)=\lambda x[\pi(x, D I R T Y)]
$$

It might be objected at this point that positing two denotations amounts to simply stipulating two distinct lexical entries for $-k a$, which would significantly undermine the main ambition of this paper, namely to provide an explanation of the syncretism of possessive and PC $-k a$. Indeed, as a reviewer points out, the two denotations are type theoretically different. When $\mathrm{ka}_{1}$ combines with all its arguments, it returns a set of individuals, whereas when $\mathrm{ka}_{2}$ does so it returns a truth value. It must therefore be acknowledged that $-k a$ is associated with two distinct model theoretic objects in each case.

However, we maintain that this is a fairly superficial difference, since these two distinct model theoretic objects are related in a systematic way. Specifically, the truth condition contributed by $-k a$ to any sentence in which this morpheme occurs is simply that two individuals are related by the possessive relation $\pi$. Consider the resulting expression when $\mathrm{ka}_{1}$ and $\mathrm{ka}_{2}$ are fully saturated, say by an individual $a$ and a predicate $P_{1}$ in the first case, and by two individuals $a$ and a property $p_{1}$ in the second. The resulting expressions are in (54). 


$$
\begin{array}{ll}
\text { a. } & \lambda y\left[\pi(a, y) \& P_{1}(y)\right] \\
\text { b. } & \pi\left(a, p_{1}\right)
\end{array}
$$

What must a model be like in order that the function in (54a) ever return the value 1 ? It must be such that the set of $a$ 's $\pi$-successors in the extension of $P_{1}$ is not empty. Similarly, what must a model be like in order for the expression in $(54 \mathrm{~b})$ to denote 1 ? It must be such that the set of $a$ 's $\pi$-successors in the domain of properties include $p_{1}$. Thus, in both cases the condition imposed by $-k a$ on the model concerns the extension of a single relation: $\pi$. A good way to conceptualize the difference between the two "meanings" of $-k a$ is in terms of the selectional restrictions they impose on the possessed entity (i.e. on the second member of an ordered pair in the extension of $\pi$ ). ka $a_{1}$ requires the possessed entity to be in the extension of some predicate $P$, whereas $\mathrm{ka}_{2}$ requires it to be a property. The combinatorial difference between the two denotations (one returns a set, the other a truth value) is very similar in kind to the difference posited in e.g. Montague Grammar between the predicative and attributive denotations of an adjective. As a predicate, an adjective denotes a predicate of type $\langle e, t\rangle$. As a modifier, it denotes a predicate modifier of type $\langle\langle e, t\rangle,\langle e, t\rangle\rangle$. The two will therefore denote two distinct model theoretic entities. Nevertheless, since in both cases the condition on truth imposed by the adjective is essentially the same, this arguably does not amount to positing lexical ambiguity for the adjective. In the case of the two denotations of $-k a$, things are slightly complicated by the fact that a sortal restriction involved in $\mathrm{ka}_{2}$ is not involved in $\mathrm{ka}_{1}$. Nevertheless, we think it is fair to say that $-k a$ uniformly contributes possessive meaning in both denotations, and hence that our analysis does not amount to positing a lexical ambiguity for $-k a$.

\subsection{Predicative constructions}

With the denotations for $-k a$ given above and the treatment of NP syntax and semantics laid out in $\S 4$, the analysis of predicative PC constructions like (48a), repeated in (55), is straightforward.

$$
\begin{aligned}
& \text { Yang as-ki-na minisih-ka. } \\
& \text { 1SING shirt-1SING dirty-KA } \\
& \text { 'My shirt is dirty.' }
\end{aligned}
$$

The syntactic analysis of (55) is give in (56). ${ }^{20}$

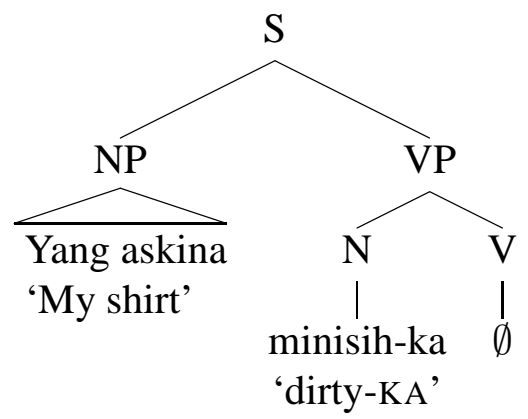

\footnotetext{
${ }^{20}$ Ulwa has an overt copula in all cells except the third person. We therefore assume a null copula in trees such as (56b). However, we view the copula as denoting the identity function on predicates following e.g., Partee (2002), and so nothing in our analysis would change if no copula were assumed.
} 
The LF formation rules laid out in $\S 4$ associate this structure with the LF in (57).

LF for (56)

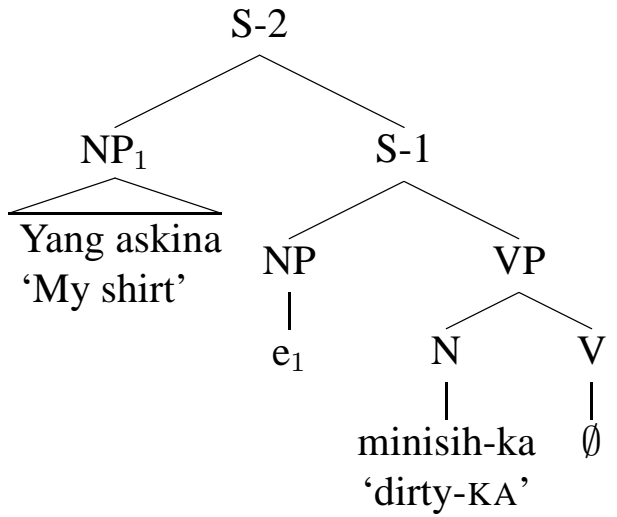

Our rules of LF interpretation derive the meaning of (57) as in (58) (We use $s p$ to denote the speaker of an utterance).

$$
\begin{array}{ll}
\text { a. } & \llbracket \mathrm{N} \rrbracket=\mathrm{ka}_{2}(\llbracket \text { minisih } \rrbracket)= \\
& \lambda \Pi_{p} \lambda x[\pi(x, \Pi)](D I R T Y)= \\
& \lambda x[\pi(x, D I R T Y)] \\
\text { b. } \quad & \llbracket \mathrm{VP} \rrbracket=\llbracket \mathrm{N} \rrbracket(\text { since we take the copula to denote the identity function on } \\
& \text { predicates; see fn. } 20) \\
\text { c. } & \llbracket \mathrm{S}-1 \rrbracket=\llbracket \mathrm{VP} \rrbracket\left(\llbracket e_{1} \rrbracket\right)= \\
& \lambda x[\pi(x, D I R T Y)]\left(x_{1}\right)= \\
& \pi\left(x_{1}, D I R T Y\right) \\
\text { d. } & \llbracket \mathrm{S}-2 \rrbracket=\llbracket \mathrm{NP}_{1} \rrbracket\left(x_{1}\right) \& \llbracket \mathrm{S}-1 \rrbracket= \\
& \lambda x[\pi(\operatorname{sp}, x) \& \operatorname{shirt}(x)]\left(x_{1}\right) \& \pi\left(x_{1}, D I R T Y\right)= \\
& \pi\left(\operatorname{sp}, x_{1}\right) \& \operatorname{shirt}\left(x_{1}\right) \& \pi\left(x_{1}, D I R T Y\right)
\end{array}
$$

The denotation of the sentence, as shown in (58d), is an open formula, subject to default existential closure, making the sentence true iff there exists an entity that is a shirt possessed by the speaker that has the dirtiness property (ignoring the issues of familiarity/uniqueness).

\subsection{Attributive constructions}

Examples of PC words with $-k a$ in attributive position are given in (59).

a. Baka basa-ka ya âmh-dida.

child small-KA the yawn-3SING.PAST

'The small child yawned.'

(0405-1037)

b. Nangtak kasar-ka balna ya dut-ka tal-yang.

nose down.curved-KA PL DEF bad-KA see-1SING.PRES

'I look badly upon down-curved noses.'

c. Kasna dam-ka wâlik kas-yang.

food sweet-KA only eat-1SING.PRES

'I only eat sweet food.'

d. Muih auh-ka ya yam-ka ka katka panil-wa-naka ya person fat-KA DEF good-KA SENT-KA but tree climb-WA-3SING.INF the 
dî makun-ka ka.

thing pathetic-KA SENT-KA

'A fat person is good, but pathetic when it comes to climbing a tree.' (Green 2004:auhka)

The most obvious treatment of such examples is to analyze the PC words simply as modifiers modifying an adjacent noun, with semantic composition proceeding by way of a rule of predicate modification as in e.g. Heim and Kratzer (1998). The facts, however, support a different kind of analysis. First, Koontz-Garboden (2007:161-169) lays out a series of arguments that PC roots suffixed with $-k a$ are nouns, not adjectives. One of the properties characterizing nouns crosslinguistically is not being able to attributively modify nouns (Croft 1990; Bhat 1994; Wetzer 1996; Beck 2002; Baker 2003). Furthermore, it is not only PC words that can appear string adjacent to a noun internal to an NP; the same is true for verbs (60a) and non-PC nouns (60b).

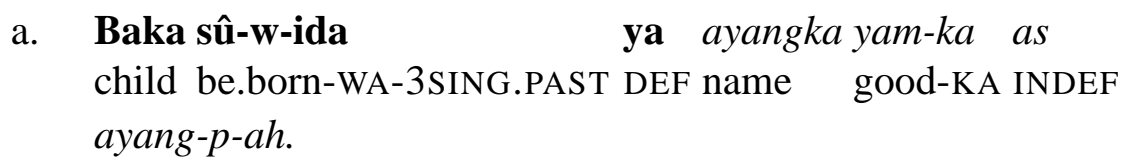

b. Wahai-ki watyu ya damai muih as $\hat{\imath}$-wa-na

brother-1SING healer DEF yesterday person INDEF sick-WA-NOMZ

wâ-t-ak umh-p-ida.

catch-TA-3SING.DS help-PA-3SING.PAST

'Yesterday, my brother who is a healer helped a person who had caught a sickness.'

(Mar06-36)

Analyzing the sentences in (60) as involving attributive uses of verbs (60a) and nouns (60b) would go against the generalization that only adjectives attributively modify nouns (Hengeveld 1992; Bhat 1994; Beck 2002; Baker 2003). This is one of the reasons why similar constructions in the related language Miskitu have been analyzed as internally headed relative clauses (IHRCs; Alpher and Hale n.d., Green 1992). For example, the subject NP in (60b) has the syntactic structure in (61), with a null copula in the third person, similarly to matrix sentences with a main nominal predicate (on which, see the discussion in Koontz-Garboden 2007:Chapter 4).

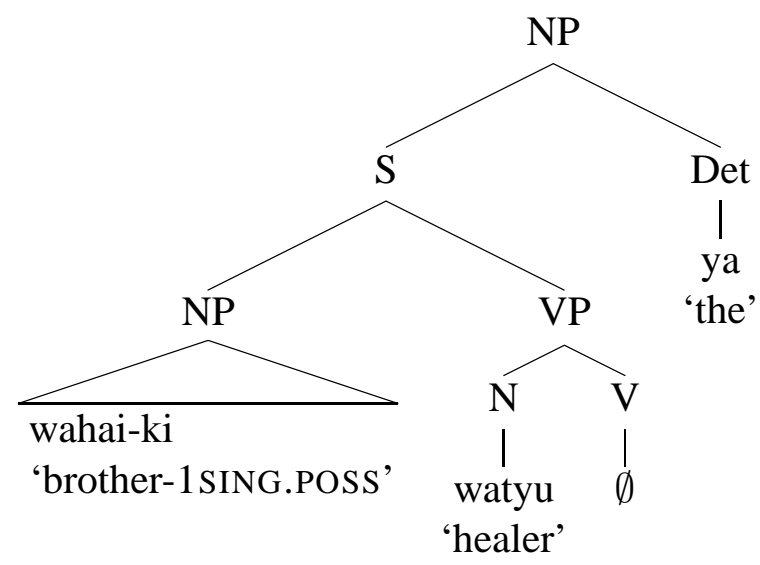


As Green (1992) points out for Miskitu, there is also no reason not to analyze what look like attributive uses of PC words like those in (59) as IHRCs with a structure essentially the same as (61), the PC word acting as the main predicate. The grammar of Miskitu, and Ulwa like it, independently generates such structures, and, as Green shows, there is no evidence pointing to a separate attributive construction. Green (1992) observes further that the analysis of NP-internal PC words as predicates internal to IHRCs fits well with Ulwa's rigid head-final structure. Given Ulwa's head-final syntactic structure, the relative ordering of the noun and the PC word ( $\mathrm{N}-$ PC word) in an attributive construction is expected. If the relevant constructions are not IHRCs, however, there is no obvious explanation for a Noun - Modifier order in what is otherwise a head-final language. These considerations, together with the fact that Ulwa lacks adjectives, and that PC words suffixed with $-k a$ are nouns, lead us to adopt an IHRC analysis of Ulwa attributive constructions. In other words, attributive constructions are explained away as special instances of predicative constructions.

We broadly adopt the syntax generally assumed for IHRCs in the literature (Cole 1987; Culy 1990; Green 1992; Basilico 1996), the crucial analytical point of which is that an IHRC is an NP that has a sentence rather than a noun as the sister of a determiner. We also follow Culy (1990:96) in positing a null wh-operator coindexed with the head of the relative clause. ${ }^{21}$ Thus, a sentence like (62a) receives the analysis in (62b).

a. Baka basa-ka ya âmh-dida.

child small-KA the yawn-3SING.PAST

'The small child yawned.'

(0405-1037)

b.

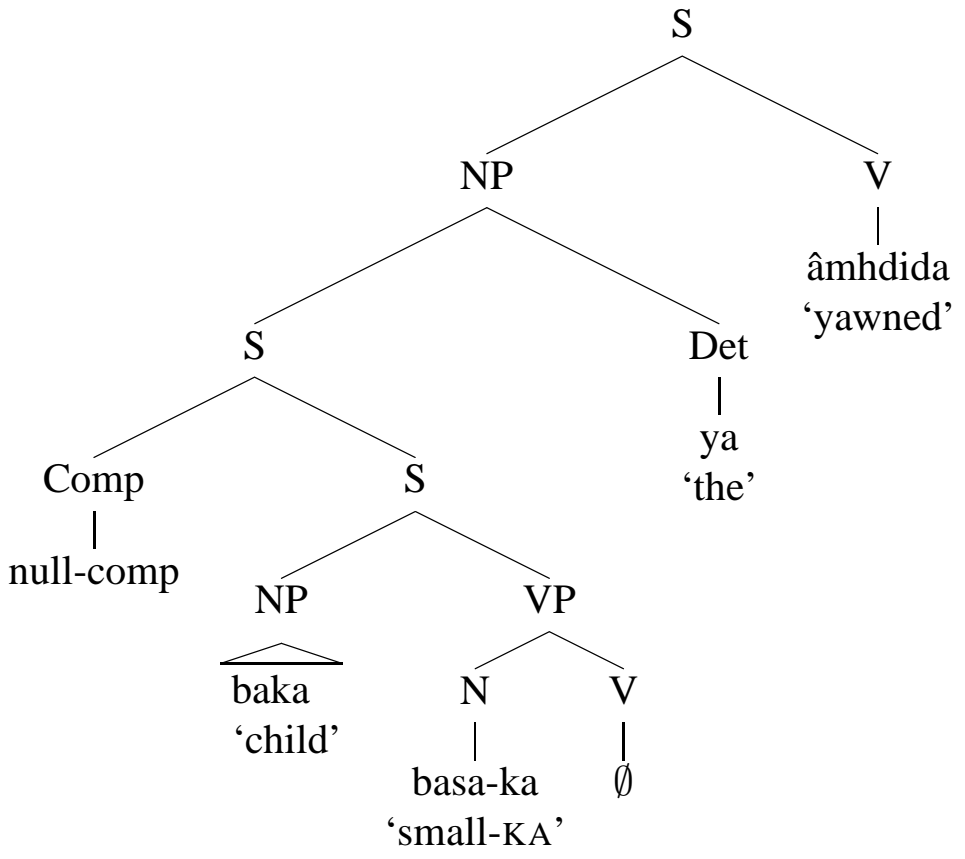

Our rules for generating LFs assign (62a) the LF in (63).

(63) LF for Baka basaka ya âmhdida. 'The small child yawned.'

\footnotetext{
${ }^{21}$ Although the wh-operator plays little role in the syntactic analysis, it does play an important role in the semantic analysis we develop below. In the words of Culy "if the $w h$ operator is not present, then the nominalized sentence will be a complement and interpreted as a proposition" (Culy 1990:95, fn. 24). Instead, what the whoperator does is to turn the denotation of the nominalized sentence into that of a description.
} 


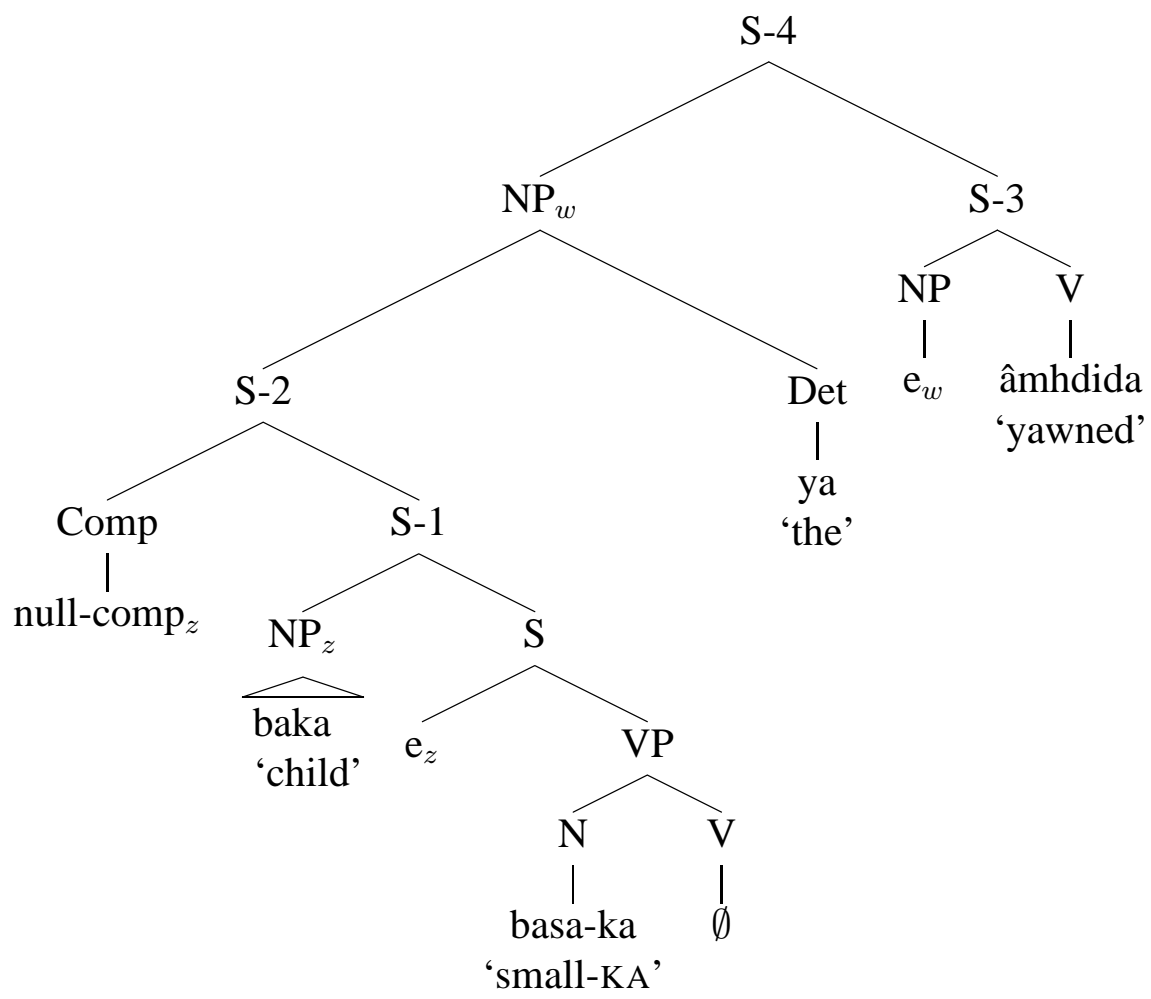

The difference between the surface syntactic structure in (62b) and the LF in (63) is a consequence of several instances of the rule of NP-adjoining, which applies to all NPs other than names and pronouns. On the theory we adopted above, argument NPs are raised and adjoined to the lowest $\mathrm{S}$, while possessor NPs are raised and adjoined to NP. Coindexed traces are left behind by both types of movement, generating the LF in (63). The derivation in (64) shows how the LF in (63) is interpreted, given our analysis of PC $-k a$. The meaning of the sentence is an open formula with free variables bound at the clause level.

$$
\begin{aligned}
& \text { a. } \quad \llbracket \mathrm{N} \rrbracket=\lambda x[\pi(x, S M A L L)] \\
& \text { b. } \quad \llbracket \mathrm{VP} \rrbracket=\llbracket \mathrm{N} \rrbracket=\lambda x[\pi(x, S M A L L)] \\
& \text { c. } \quad \llbracket \mathrm{S} \rrbracket=\llbracket \mathrm{VP} \rrbracket\left(\llbracket e_{z} \rrbracket\right)=\lambda x[\pi(x, S M A L L)](z)=\pi(z, S M A L L) \\
& \text { d. } \quad \llbracket \mathrm{S}-1 \rrbracket=\llbracket \mathrm{NP}_{x} \rrbracket(x) \& \llbracket \mathrm{S} \rrbracket=\operatorname{child}(z) \& \pi(z, S M A L L) \\
& \text { e. } \quad \llbracket \mathrm{S}-2 \rrbracket=\lambda x[\operatorname{child}(x) \& \pi(x, S M A L L)] \text { (by predicate abstraction) } \\
& \text { f. } \quad \llbracket \mathrm{NP}_{w} \rrbracket=\llbracket \mathrm{S}-2 \rrbracket \\
& \text { g. } \quad \llbracket \mathrm{S}-3 \rrbracket=\llbracket \mathrm{VP} \rrbracket\left(\llbracket e_{w} \llbracket\right)=\lambda x[\operatorname{yawned}(x)](w)=\operatorname{yawned}(w) \\
& \text { h. } \quad \llbracket \mathrm{S}-4 \rrbracket=\llbracket \mathrm{NP}_{w} \rrbracket(w) \& \llbracket \mathrm{S}-3 \rrbracket= \\
& \lambda x[\operatorname{child}(x) \& \pi(x, S M A L L)](w) \& \operatorname{yawned}(w)= \\
& \operatorname{child}(w) \& \pi(w, S M A L L) \& \operatorname{yawned}(w)
\end{aligned}
$$

To summarize, we have made two crucial assumptions in the analysis of $-k a$ with PC roots:

- PC roots denote properties.

- Ulwa has no attribution. Apparently attributive contexts involve IHRCs.

These assumptions allow us to analyze the semantic contribution of $-k a$ as uniformly possessive, and to formalize our explanation of the syncretism. This explanation can be summarized as in (65). 


\section{Summary of the argument:}

a. PC roots require affixation to function as free syntactic words. The derived words contribute predicates that have the same truth conditional effect as their adjectival counterparts in other languages.

b. PC roots denote properties.

c. In order for PC roots to serve as predicates, one of two strategies must be employed:

(i) UP-strategy: The property denotation of the root component is mapped to its corresponding predicate (by the $\cup$ operator)

(ii) HAVE-strategy: The property denotation of the root component is mapped to the set of individuals who have the property (the individuals that stand in the $\pi$ relation to it).

d. Ulwa has a possessive morpheme, $-k a$, which figures in possessive constructions. Ulwa does not have an (overt) affix realizing the operator mapping properties to their corresponding predicates. It therefore utilizes the HAVE-strategy.

Note that this analysis in consistent with the fact, discussed in $\S 3.2$, examples (24) and (25), that given the right morphophonological context, Ulwa allows roots to occur without $-k a$. In that case, we assume the UP-strategy is employed, with the $\cup$ operator functioning as a covert type shifter.

\section{Extensions}

An interesting and welcome consequence of the proposed analysis is that it affords a compositional account for an otherwise peculiar construction involving $-k a$, which we call the 'double $-k a$ ' construction. It also sheds light on a construction in which PC words are used with watah 'have.' We discuss these two constructions in turn.

\section{1 'Double $-k a$ ' constructions}

In the double $-k a$ construction, illustrated in (66), PC words in $-k a$ undergo a second round of $-k a$ affixation (see also Green 1999:135). ${ }^{22}$

$$
\begin{array}{ll}
\text { a. Bilam sikamh-ka-ka raupi y-â-tak } & k a n g \\
\text { fish stinky-3SING-KA RAUPI 1SING.NON-NOM-cause-3SING.DS APPL } \\
\text { lâ-wa-yang } \quad \text { Bob ya bilam watah ka. } \\
\text { cross-WA-1SING.PRES Bob DEF fish have SENT-KA }
\end{array}
$$

'The stinkiness of the fish makes me aware that Bob has fish.'

(Mar06-56)

b. Dut-ki-ki luk-t-ah.

bad-1SING-KA lose-TA-2SING.IMP

'Forget the badness that I did.' or "“My bad”, forget it.'

(Mar06-123)

\footnotetext{
${ }^{22}$ On the surface, $d u t-k i-k i$ in (66b) would be expected to have the phonological shape $d u t-k i-k a$ (the 1 SING possessive marking infixing to the leftmost iamb, as discussed above). According to Green (1999:81), this is actually attested. The form in (66b), by contrast, is also attested, and Green conjectures, appears as a result of influence from Miskitu of a phonological process that raises $a$ to $i$ in possessive suffixes in certain contexts. See Green (1999:81) for details.
} 
c. Pâpangh-ni dasi-ka-ka kau baka-ki ya andih ala-t-i

father-1INCL.PL strong-3SING-KA with child-1SING DEF already raise-TA-SS

bata-ka yak-t-ikda.

youth-KA extract-TA-1 SING.PAST

'With the strength of god, I have already raised my child into a youth.' (0405-474)

Semantically, what is interesting about these constructions is that they involve what can be described as a change in semantic headedness. While the semantic head of the NP bilam sikamhka 'smelly fish' is bilam 'fish', the semantic head of bilam sikamhkaka, roughly, 'the fish's stench' is sikamhkaka. The analysis we have proposed predicts exactly this behavior. Moreover, it predicts that double $-k a$ marking can only involve PC roots, that there can be no more than two occurrences of $-k a$ affixation to the PC root-one denoting $\mathrm{ka}_{2}$ and the other denoting $\mathrm{ka}_{1}$, and that composition with the denotation of the $\mathrm{PC}$ root is in precisely that order.

Consider first the intuitive meaning of these constructions. The meaning of a noun like Dut-ki-ki, as the gloss shows, is something like 'my sins'. A sin is something bad, i.e. a thing that has badness. The NP can thus be though of as meaning 'my bad thing'. On our analysis, the grammar of Ulwa mirrors this suggestive decomposition. The root $d u t$, we are assuming, denotes the property of badness - the property that all bad things instantiate. The meaning of the NP calls for relating this property to the speaker by the possessive relation. However, given the facts of Ulwa grammar, a root like $d u t$ cannot enter directly into a possessive relation with a noun. In order to do so, it must be turned into a noun and must take a specifier. We know from the descriptive facts that roots are turned into words by $-k a$ affixation. The possessive morpheme $\mathrm{ka}_{1}$ cannot compose with the root and turn it into a noun, since its type requires it to compose with a predicate. To repair this, the root is composed instead with $\mathrm{ka}_{2}$, yielding a noun that denotes the set of bad things (strictly speaking, the set of things that have the BADNESS property). This noun now has an $\langle e, t\rangle$ denotation, i.e., the kind of denotation that allows it to compose with $\mathrm{ka}_{1}$, and thus allows it to compose with a possessor (in the example in question, the omitted first person pronoun), thus yielding a possessive NP that denotes a description: a bad thing of mine.

As a point of departure for the analysis, we observe that the words in question (e.g. sikamhka) behave, morphologically, like possessed nouns in that they can occur with possessors of any person and number, as first shown by Green (1999:81). As expected, the second round of possessive marking agrees in both person and number with the possessor. ${ }^{23}$ For example, the full paradigm for sang-ka-ka 'his/her greenness/life' is given in (67).

$$
\begin{array}{cccll}
\multicolumn{2}{l}{\text { sang ('green, alive') }} & (\text { Green 1999:81) } & & \\
\text { 1SING } & \text { sang-ki-ka } & \text { 'my greenness/life' } & \text { 1PL.INL } & \text { sang-ni-ka 'our greenness/life' } \\
& & & \text { 1PL.EXCL } & \text { sang-kina-ka 'our greenness/life' } \\
\text { 2SING } & \text { sang-ma-ka } & \text { 'your greenness/life' } & \text { 2PL } & \text { sang-mana-ka 'your (pl) greenness/life' } \\
3 \text { SING } & \text { sang-ka-ka } & \text { 'his/her/its greenness/life' } & \text { 3PL } & \text { sang-kana-ka 'their greenness/life' }
\end{array}
$$

Syntactically, we analyze these constructions as perfectly regular possessive NPs. The possessed noun is the head, with the possessor NP in the specifier. Possessive morphology on the head noun agrees in person and number with the possessor NP in the specifier. This is

\footnotetext{
${ }^{23}$ Green (1999:81) lists a couple of dialectal variants for the first singular, third singular, and first plural inclusive, which are not relevant for the points we are making here, so we leave them to the side. For the full set of possible forms across all speakers, see Green (1999:81).
} 
illustrated for bilam sikamh-ka-ka in (68).

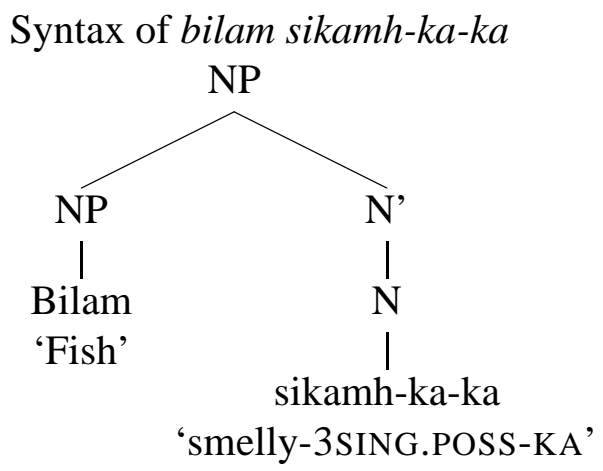

Our analysis assigns the LF in (69) to this structure (the possessor NP is raised and adjoined by the rule of NP-adjunction described in $\S 4$ ).

$$
\text { LF of bilam sikamh-ka-ka }
$$

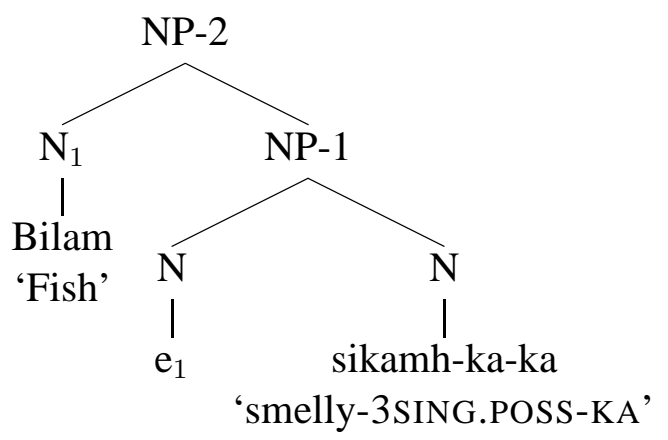

The derivation in (71) shows how, given the denotations for bilam 'fish' and the PC root sikamh - 'smellyness' in (70), our analysis generates the correct meaning for (68), namely a description describing the set of things that have smellyness that are related by the possessive relation to the fish. Following the notation from before, we use SMELLY as the constant of type $p$ which denotes the property of being smelly.

$$
\begin{array}{ll}
\text { a. } & \llbracket \text { bilam } \rrbracket=\lambda x[\text { fish }(x)] \\
\text { b. } & \llbracket \text { sikamh- } \rrbracket=S M E L L Y \\
\text { a. } & \llbracket \text { sikamh-ka } \rrbracket=\text { ka }_{2}(\llbracket \text { sikamh- } \rrbracket)= \\
& \lambda \Pi_{p} \lambda x[\pi(x, \Pi)](S M E L L Y)= \\
& \lambda x[\text { pi }(x, S M E L L Y)]
\end{array}
$$
a. $\quad \llbracket$ sikamh-ka $\rrbracket=\mathrm{ka}_{2}(\llbracket$ sikamh- $\rrbracket)=$ $\lambda \Pi_{p} \lambda x[\pi(x, \Pi)](S M E L L Y)=$

b. $\quad \llbracket$ sikamh-ka-ka $\rrbracket=\mathrm{ka}_{1}(\llbracket$ sikamh-ka $\rrbracket)=$ $\lambda P_{\langle e, t\rangle} \lambda x \lambda y[\pi(x, y) \& P(y)](\lambda x[\pi(x, S M E L L Y)=$ $\lambda x \lambda y[\pi(x, y) \& \pi(y, S M E L L Y)]$

c. $\quad \llbracket \mathrm{NP}-1 \rrbracket=\llbracket$ sikamh-ka-ka $\rrbracket\left(\llbracket e_{z} \rrbracket\right)=$ $\lambda x \lambda y[\pi(x, y) \& \pi(y, S M E L L Y)](z)=$ $\lambda y[\pi(z, y) \& \pi(y, S M E L L Y)]$

d. $\quad \llbracket \mathrm{NP}-2 \rrbracket=\lambda u\left[\llbracket \mathrm{N}_{z} \rrbracket(z) \& \llbracket \mathrm{NP}-1 \rrbracket(u)\right]=$ $\lambda u[\lambda x[\operatorname{fish}(x)](z) \& \lambda y[\pi(z, y) \& \pi(y, S M E L L Y)](u)=$ $\lambda u[f i s h(z) \& \pi(z, u) \& \pi(u, S M E L L Y)]=$ 'the set of things that have smellyness that are $\pi$-related to the fish' 
Given this state of affairs, our analysis predicts that there should be nothing comparable to the double $-k a$ construction with nouns, as opposed to PC roots, since only PC roots denote properties, and therefore only they, and not nouns, can compose with $\mathrm{ka}_{2}$. In over 14 months of fieldwork, we have never heard anything like (72). ${ }^{24}$

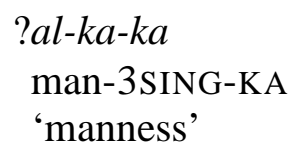

Based at least on our current knowledge, and Green's (1999:81-82;135-136) description of the double $-k a$ construction as applying to Ulwa "adjectivally marked adjective stems" (Green 1999:81; i.e., $-k a$ marked PC roots, in our terminology), we suspect that (72) is indeed ungrammatical. However, corroborating this beyond doubt will require further fieldwork.

\footnotetext{
${ }^{24}$ Our analysis, as must any analysis of possessive NPs, allows for multiple embeddings of possessors, with multiple possessive marking on the possessor of each possessed noun. Such constructions, exemplified by the data in (i), are commonplace in Ulwa.

(i)

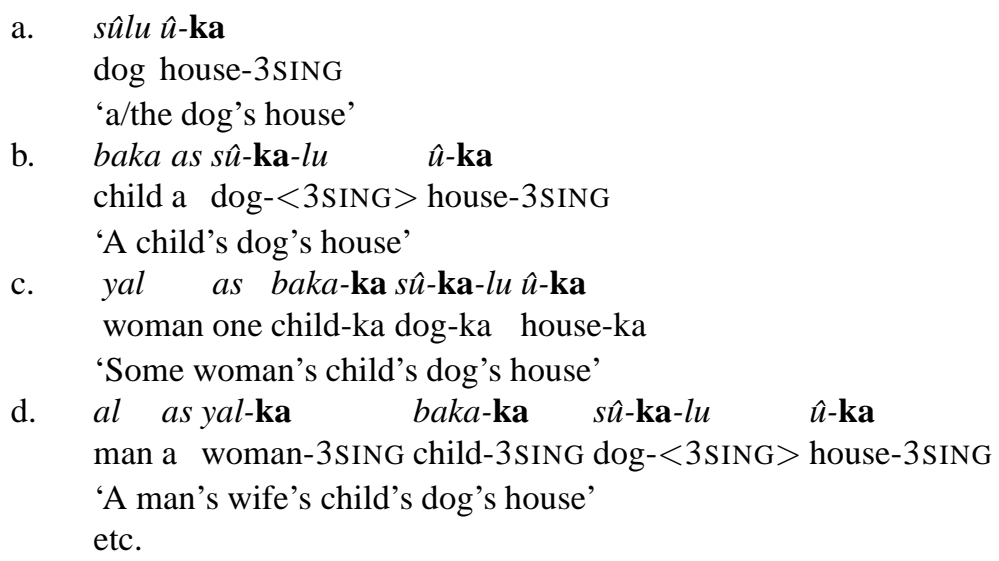

The syntactic structure for (ic), for example, is given in (ii), with each possessed noun, as above, taking a possessive specifier, the only difference being that except for the head noun, $\hat{u}-k a$ 'house-3SING.POSS', the possessed nouns are also possessors themselves.
}

(ii)

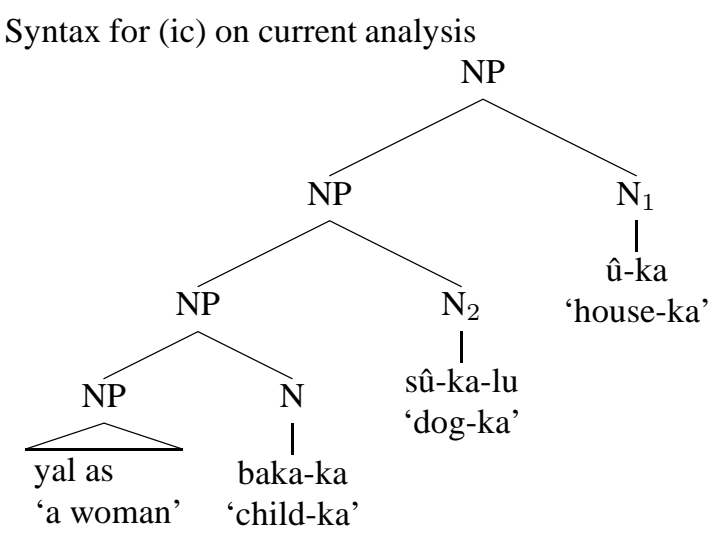

The LF generation rules discussed above, given the syntactic structure in (ii), generate the LF in (iii), with each possessive NP undergoing NP-adjunction and adjoining to the maximal NP.

(iii) LF for (ic) on current analysis 
To summarize, this section demonstrated how the analysis we propose straightforwardly captures the facts of double- $k a$ constructions, accounting in particular for the shift in semantic headedness involved. At the same time, the analysis explains the relative order of composition with the $\mathrm{PC}$ root of $\mathrm{ka}_{1}$ and $\mathrm{ka}_{2}$ in this construction, predicting correctly that the latter composes with the PC root, the entire construct then composing with the former at the same time that a possessor is introduced in the specifier. Further, the analysis also predicts the absence of double $-k a$ constructions with nominals.

\subsection{Have+PC constructions}

Another construction which our analysis sheds light on is the use of the Ulwa watah 'have' with PC words with and without $-k a$, as exemplified in (73) and (74) respectively. As the glosses show, these examples yield meanings that are equivalent to simple predication, and we show here that this is indeed the meaning derived for them given what has been assumed so far.

a. Jessicabas-ka ya tubak-ka, salai-ka, yûh-ka palkawatah ka. Jessica hair-3SING the thick-KA smooth-KA long-KA very have SENT-KA 'Jessica's hair is thick, smooth, and very long.'

(Oct09-134)

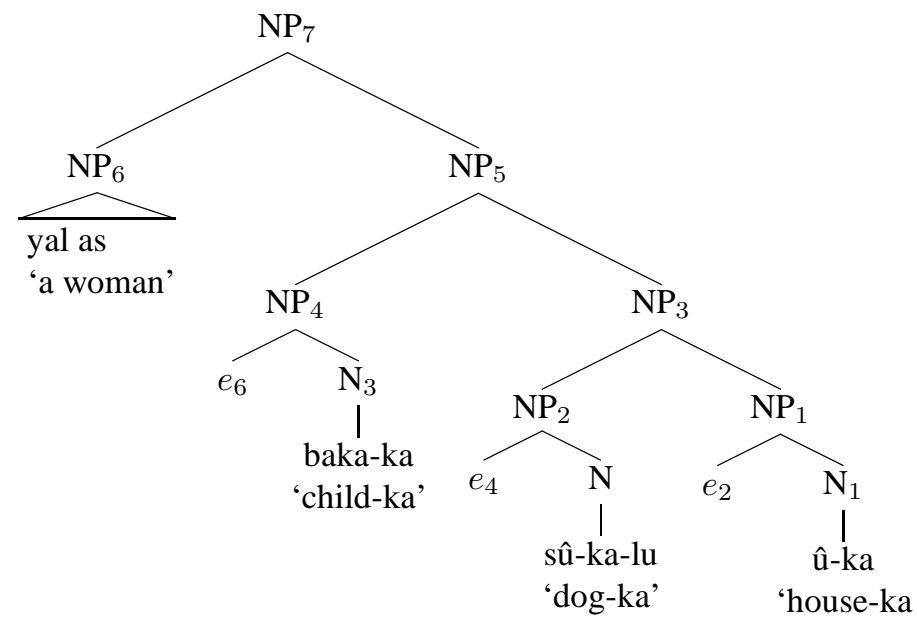

The derivation in (iv) shows how our analysis derives the meaning of the multiply-embedded possessive NP in (iii).

(iv) Interpretation:

a. $\llbracket \mathrm{NP}_{1} \rrbracket=\lambda x[\pi(2, x) \& \operatorname{house}(x)]$

b. $\quad \llbracket \mathrm{NP}_{2} \rrbracket=\lambda y[\pi(4, y) \& \operatorname{dog}(y)]$

c. $\llbracket \mathrm{NP}_{4} \rrbracket=\lambda y[\pi(6, y) \& \operatorname{child}(y)]$

d. $\llbracket \mathrm{NP}_{6} \rrbracket=\lambda x[\operatorname{woman}(x)]$

e. $\quad \llbracket \mathrm{NP}_{3} \rrbracket=$ (by SEM1) $\lambda u\left[\llbracket \mathrm{NP}_{2} \rrbracket(2) \& \llbracket \mathrm{NP}_{1} \rrbracket(u)\right]=$ $\lambda u[\pi(4,2) \& \operatorname{dog}(2) \& \pi(2, u) \&$ house $(u)]$

f. $\quad \llbracket \mathrm{NP}_{5} \rrbracket=$ (by SEM1) $\lambda v\left[\llbracket \mathrm{NP}_{4} \rrbracket(4) \& \llbracket \mathrm{NP}_{3} \rrbracket(v)\right]=$ $\lambda v[\pi(6,4) \& \operatorname{child}(4) \&(\lambda u[\pi(4,2) \& \operatorname{dog}(2) \& \pi(2, u) \&$ house $(u)])(v)]=$ $\lambda v[\pi(6,4) \& \operatorname{child}(4) \& \pi(4,2) \& \operatorname{dog}(2) \& \pi(2, v) \&$ house $(v)]$

g. $\quad \llbracket \mathrm{NP}_{7} \rrbracket=\left(\right.$ by SEM1) $\lambda q\left[\llbracket \mathrm{NP}_{6} \rrbracket(6) \& \llbracket \mathrm{NP}_{5} \rrbracket(q)\right]=$ $\lambda q[\lambda x[\operatorname{woman}(x)](6) \& \lambda v[\pi(6,4) \&$ child $(4) \& \pi(4,2) \& \operatorname{dog}(2) \& \pi(2, v) \&$ house $(v)](q)]=$ $\lambda q[\operatorname{woman}(6) \& \pi(6,4) \& \operatorname{child}(4) \& \pi(4.2) \& \operatorname{dog}(2) \& \pi(2, q) \&$ house $(q)]=$ 'the set of houses $q$ owned by a dog 2 owned by a child 3 ...' 
b. Yang tal-yang yang $\hat{u}-k i \quad$ karakUlwa $\hat{u}-k a \quad$ ya kanas 1 SING see-1SING 1 SING house-1SING with Ulwa house-3SING the more mau-ka watah ka. clean-KA have SENT-KA

'Between my house and the Ulwa house (=the house of the Ulwa Language Project), my house is cleaner.'

(Oct09-134)

a. Laura bas-ka yâ laih turus watah ka.

Laura hair-3SING that TOP curly have SENT-KA

'As for Laura's hair, it's curly.'

(Oct09-134)

b. Yâka û-ka yâka yûh-ka. An tarat watah ka.

that house-3SING that long-KA. and tall have SENT-KA

'That house is long. And it's tall.'

(Oct09-109)

Speakers do not have stable judgments of such constructions in elicitation, but they are not infrequent in discourse and the examples in (73) and (74) were spontaneously produced.

On our analysis, the constructions with and without $-k a$ receive different, but semantically equivalent, interpretations. Variants lacking $-k a$ like those in (73) are trivial to account for on our analysis. The property denoting PC root combines directly with watah, which we take to denote the possessive relation $\lambda x \lambda y . \pi(x, y)$. The resulting predicate is the same one as is expressed by a PC root suffixed with $\mathrm{ka}_{2}$.

The variants with $-k a$ in (73) might at first seem somewhat surprising given our assumption that $\mathrm{PC}$ words with $-k a$ express $\langle e, t\rangle$ predicates. However, the interpretation predicted is in fact fairly straightforward. Consider, for example, the simplified version of (73b) in (75)

Ulwa $\hat{u}-k a \quad$ ya mau-ka watah ka.

Ulwa house-3SING the clean-KA have SENT-KA

'The Ulwa house is clean.'

This sentence receives the syntactic analysis in (76), and the LF in (77) (by two instances of NP-adjunction).

Syntax for (75)

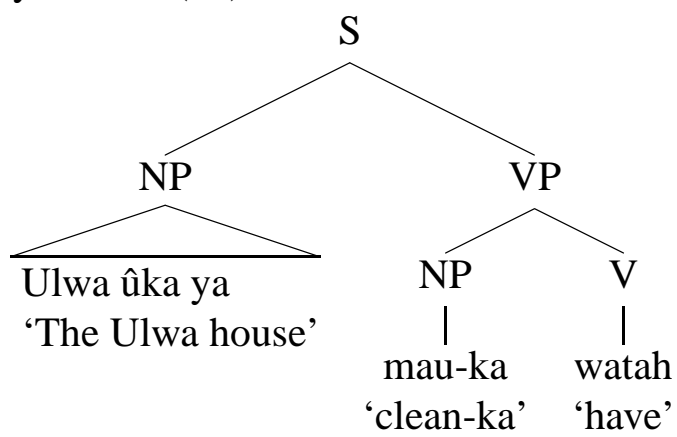

(77)

LF for (75) 


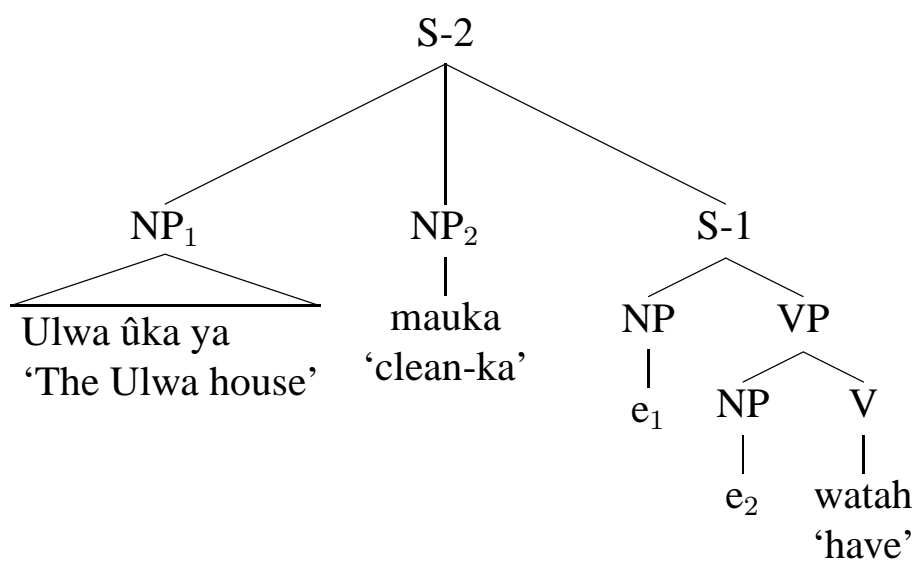

The derivation in (78) shows the truth conditions generated for (75).

(78) Derivation for (77)

$$
\begin{array}{ll}
\text { a. } & \llbracket \mathrm{V} \rrbracket=\lambda x \lambda y[\pi(x, y)] \\
\text { b. } & \llbracket \mathrm{VP} \rrbracket=\llbracket \mathrm{V} \rrbracket\left(\llbracket e_{2} \rrbracket\right)= \\
& \lambda x \lambda y[\pi(x, y)]\left(x_{2}\right)= \\
& \lambda y\left[\pi\left(x_{2}, y\right)\right] \\
\text { c. } & \llbracket \mathrm{S}-1 \rrbracket=\llbracket \mathrm{VP} \rrbracket\left(\llbracket e_{1} \rrbracket\right)= \\
& \lambda y\left[\pi\left(x_{2}, y\right)\right]\left(x_{1}\right)= \\
& \pi\left(x_{2}, x_{1}\right)
\end{array}
$$

d. by two applications of SEM2, $\llbracket \mathrm{S}-2 \rrbracket=\llbracket \mathrm{NP}_{1} \rrbracket\left(x_{1}\right) \& \llbracket \mathrm{NP}_{2} \rrbracket\left(x_{2}\right) \& \llbracket \mathrm{S}-1 \rrbracket=$ $\lambda y[\pi$ (Ulwa language, $y) \&$ house $(y)]\left(x_{1}\right) \& \lambda x[\pi(x, C L E A N)]\left(x_{2}\right) \& \pi\left(x_{2}, x_{1}\right)=$ $\pi\left(\right.$ Ulwa language, $\left.x_{1}\right) \&$ house $\left(x_{1}\right) \& \pi\left(x_{2}, C L E A N\right) \& \pi\left(x_{2}, x_{1}\right)$

After existential closure, the derivation in (78) correctly predicts that (75) is true iff there is a house that stands in the possessive relation to the Ulwa language, and there exists some other entity standing in the possessive relation to the CLEAN property, and the Ulwa house stands in the possessive relation to that entity. I.e., (75) is true if the Ulwa house possesses something that possesses cleanliness.

One might wonder why examples like (75) are ever produced, i.e. why they are not blocked by their simpler variants without $-k a$, or indeed by simple predicative variants. While we cannot provide a definitive answer, we conjecture that this is an idiomatic construction similar to the English one exemplified in (79a) and (79b).
a. Kim is special.
b. Kim has something special about him.

The construction in (79b) parallels the one in (75). The English construction is, as far as we know, rather limited and unproductive. The Ulwa construction seems to be much more productive, though we do not know exactly to what extent it is. Perhaps this is not altogether surprising, given that, as we argue, Ulwa makes a much wider use of possessive strategies of predication than does English. Clearly, this construction deserves more study. However, the upshot is that these constructions receive correct interpretations on our analysis. 


\section{Concluding remarks and outstanding issues}

This paper proposed an explanation for the syncretism between possessive morphology and marking on property concept words in Ulwa. We presented facts from Misumalpan diachrony that, we believe, suggest beyond doubt that the possessive/PC syncretism is not accidental in Ulwa, and observed furthermore that the same pattern is found across a range of unrelated languages. A syntax and semantics for the relevant constructions was then presented. For possession, we adopted straightforwardly Barker's (1995) theory of possessive descriptions. In the case of PC marking, we showed that its presence (absence) is morphophonologically determined: PC roots cannot function as stand alone syntactic words, and require affixation unless a bimoraic adjacent host is present. The crucial question was why the relevant marking should be syncretic with possessive marking, and our answer is that the choice of marking is semantically determined. Specifically, we suggested that PC roots denote primitive properties which cannot be predicated. Possessive morphology maps any property to the set of individuals who have it, thus allowing properties to make a semantic contribution equivalent to (though not identical to) that of corresponding predicates in languages that have adjectives. We dubbed this a strategy for imitating predication through possession. Whether or not there is crosslinguistic justification for considering such a strategy part of universal grammar is an interesting direction for future research. Our analysis thus renders the Ulwa pattern of syncretism entirely unmysterious, and straightforwardly captures the diachronic facts described in $\S 2.2$. More broadly, we hope to have provided another example of the theoretical fruitfulness of taking syncretism at face value, by showing how seeking a grammatical motivation for a non-accidental syncretic pattern can point the way toward an insightful analysis of the facts.

There remain many outstanding questions. Within Misumalpan, we have said nothing about Ulwa's sister language Mayangna. Given our claims about diachrony, the semantic underpinnings of the syncretism would have been in full force at the time of the shift in phonological shape of the possessive suffix in Mayangna. The null hypothesis, then, would be that the facts in Mayangna should be as they are in Ulwa, modulo phonological differences. At present we have no data bearing on this issue, and leave it to future work. Beyond Misumalpan, the question arises whether our analysis extends in any natural way to similar patterns found in other, genetically unrelated, languages. At the moment, this too is difficult to judge, as the data we have available largely underdetermine the analysis. This points to the need for a broader crosslinguistic study, which we must again leave to a future occasion. Nevertheless, the detailed analysis of Ulwa presented here is an important first step, in that it forms a strict hypothesis from which to approach these questions.

\section{Acknowledgements}

This work would not have been possible without the wonderful collaboration we enjoy with members of the Ulwa Language Project, Karawala, Nicaragua: Abanel Lacayo, Lorinda Martínez Lacayo, Alberto Santiago, Francisco Santiago, Kandler Santiago and Clementina Simon. For logistical support with fieldwork in Karawala, in addition to members of the Ulwa Language Project and the community of Karawala more generally, we are grateful to: Elena Benedicto, Tom Green, Melvin James, Arja Koskinen, Guillermo Mclean, and Nubia Ordoñez. For feedback on the work presented here, we thank: Paolo Acquaviva, Karlos Arregi, Mark Baker, Luc Baronian, John Beavers, Elena Benedicto, Ricardo Bermúdez-Otero, Ashwini Deo, Edit 
Doron, Irene Heim, Yuni Kim, Paul Kiparksy, Beth Levin, John Payne, Peter Sells, Shiao Wei Tham, and Judith Tonhauser. We have also benefitted from feedback by audience members at presentations of this work at: the launch of the Institute for Linguistics and Language Studies, Manchester; Semantics of the Under-represented Languages of the Americas 4, Cambridge, MA; The Society for the Study of the Indigenous Languages of the Americas, 2008; the York/Essex Morphology Meeting 4; and the 10th Stanford Semfest. We especially thank two anonymous NALS reviewers for insightful comments that improved both the form and the content of this paper. Financial support for the fieldwork this work is based on has been provided by a Stanford GRO grant, a Fulbright-Hays grant, and funding from the British Academy.

\section{References}

Abney, Steven. 1987. The English noun phrase in its sentential aspect. Doctoral Dissertation, MIT, Cambridge, MA.

Alpher, Barry, and Kenneth L. Hale. n.d. On relativization in Miskito. Sydney University and MIT.

Baker, Mark C. 2003. Lexical categories: Verbs, nouns, and adjectives. Cambridge: Cambridge University Press.

Barker, Chris. 1995. Possessive descriptions. Stanford, CA: CSLI Publications.

Basilico, David. 1996. Head position and internally headed relative clauses. Language 72:498532.

Beck, David. 2002. The typology of parts of speech systems: The markedness of adjectives. Outstanding Dissertations in Linguistics. New York: Routledge.

Benedicto, Elena, and Ken Hale. 2000. Mayangna, a Sumu language: Its variants and its status within Misumalpan. In Indigenous languages, ed. Elena Benedicto, volume 20. Amherst, MA: University of Massachusetts Occassional Papers in Linguistics.

Bhat, D.N. 1994. The adjectival category: Criteria for differentiation and identification. Amsterdam: John Benjamins.

Bittner, Maria. 1999. Concealed causatives. Natural Language Semantics 1-78.

Campbell, Lyle. 1997. American Indian languages: The historical linguistics of Native America. Oxford: Oxford University Press.

Chierchia, Gennaro. 2004. A semantics for unaccusatives and its syntactic consequences. In The unaccusativity puzzle, ed. Artemis Alexiadou, Elena Anagnostopoulou, and Martin Everaert, 22-59. Oxford: Oxford University Press. Previously circulated as unpublished 1989 Cornell University manuscript.

Chierchia, Gennaro., and Raymond. Turner. 1988. Semantics and property theory. Linguistics and Philosophy 11:261-302.

Cole, Peter. 1987. The structure of internally headed relative clauses. Natural Language and Linguistic Theory 5:277-302.

Croft, William. 1990. Possible verbs and the structure of events. In Meanings and prototypes, ed. Savas L. Tsohatzidis, 48-73. London: Routledge.

Culy, Christopher. 1990. The syntax and semantics of internally headed relative clauses. Doctoral Dissertation, Stanford, Stanford, CA.

Dixon, R.M.W. 1982. Where have all the adjectives gone?: And other essays in semantics and syntax. The Hague: Mouton. 
Dowty, David. 1979. Word meaning and Montague grammar. Dordrecht: D. Reidel Publishing. Green, Thomas. 1992. Covert clause structure in the Miskitu noun phrase. Unpublished MIT ms.

Green, Thomas. 1999. A lexicographic study of Ulwa. Doctoral Dissertation, MIT, Cambridge, MA.

Green, Thomas. 2004. Electronic version of dictionary in Green (1999). Unpublished raw XML.

Hale, Kenneth L. 1991. Misumalpan verb sequencing constructions. In Serial verbs: Grammatical, comparative, and cognitive approaches, ed. Claire Lefebvre, 1-35. Amsterdam: John Benjamins.

Hale, Kenneth L. 1997. The Misumalpan causative construction. In Essays on language function and language type, ed. Joan Bybee, John Haiman, and Sandra A. Thompson, 199-216. Amsterdam: John Benjamins.

Hale, Kenneth L., and Samuel Jay Keyser. 2002. Prolegomenon to a theory of argument structure. Cambridge, MA: MIT Press.

Hale, Kenneth L., and Danilo Salamanca. 2002. Theoretical and universal implications of certain verbal entries in dictionaries of the Misumalpan languages. In Making dictionaries, ed. William Frawley et al., 25-59. Berkeley, CA: University of California Press.

Haspelmath, Martin. 1990. The grammaticization of passive morphology. Studies in Language $14: 25-72$.

Haspelmath, Martin. 1999. Explaining article-possessor complementarity: Economic motivation in noun phrase syntax. Language 75:227-43.

Heim, Irene. 1982. The semantics of definite and indefinite noun phrases. Doctoral Dissertation, University of Massachusetts, Amherst. Published 1988 by Garland, New York.

Heim, Irene, and Angelika Kratzer. 1998. Semantics in generative grammar. Oxford: Blackwell.

Hengeveld, Kees. 1992. Non-verbal predication: Theory, typology, diachrony. Berlin: Mouton de Gruyter.

Kemmer, Suzanne. 1993. The middle voice. Amsterdam: John Benjamins.

Kim, Yuni. 2008. Topics in the phonology and morphology of San Francisco del Mar Huave. Doctoral Dissertation, University of California, Berkeley, Berkeley, CA.

Klaiman, M.H. 1991. Grammatical voice. Cambridge: Cambridge University Press.

Koontz-Garboden, Andrew. 2007. States, changes of state, and the Monotonicity Hypothesis. Doctoral Dissertation, Stanford University, Stanford, CA.

Koontz-Garboden, Andrew. 2009a. Anticausativization. Natural Language and Linguistic Theory 27:77-138.

Koontz-Garboden, Andrew. 2009b. Locative and existential constructions in Ulwa. The University of Manchester, ms.

Koontz-Garboden, Andrew. 2009c. Ulwa verb class morphology. International Journal of American Linguistics 75:453-512.

Koontz-Garboden, Andrew. In press. Ulwa evidentials: A preliminary overview. In Proceedings of the 14th Workshop on the Structure and Constituency of the Languages of the Americas. Vancouver: UBC Working Papers in Linguistics.

Lakoff, Robin. 1971. Passive resistance. In Proceedings of the Seventh Annual Meeting of the Chicago Linguistic Society, 149-163. Chicago, IL: Chicago Linguistic Society.

Malchukov, Andrej. 2000. Dependency reversal in noun-attributive constructions : towards a 
typology. Munich: Lincom Europa.

McCarthy, John, and Alan Prince. 1998. Prosodic morphology. In Handbook of morphology, ed. Arnold Zwicky and Andrew Spencer, 283-305. Oxford: Blackwell.

Meira, Sérgio. 2006. Stative verbs vs. nouns in Sateré-mawé and the tupian family. In What's in a verb: Studies in the verbal morphology of the languages of the Americas, ed. G.J. Rowicka and E.B. Carlin, 189-214. Utrecht: LOT.

Mendikoetxea, Amaya. 1999. Construcciones con se: Medias, pasivas e impersonales. In Gramática descriptiva de la lengua Española, ed. Ignacio Bosque and Violeta Demonte, 1631-1722. Madrid: Editorial Espasa.

Murray, Sarah E. 2008. Reflexivity and reciprocity with(out) underspecification. In Proceedings of SuB12, ed. Atle GrØnn. Oslo: ILOS.

Newman, Paul. 2000. The Hausa language: An encyclopedic reference grammar. New Haven, CT: Yale University Press.

Norwood, Susan. 1997. Gramática de la lengua Sumu. Managua: CIDCA.

Partee, Barbara. 2002. Noun phrase interpretation and type-shifting principles. In Formal semantics: The essential readings, ed. Paul Portner and Barbara Partee. Oxford: Blackwell. Originally published 1987 in J. Groenendijk, D. de Jongh, and M. Stokhof, eds., Studies in Discourse Representation Theory and the Theory of Generalized Quantifiers, Foris, Dordrecht, pp. 115-143.

Ross, Malcolm. 1998. Possessive-like attribute constructions in the Oceanic languages of Northwest Melanesia. Oceanic Linguistics 37:234-276.

Wetzer, Harrie. 1996. The typology of adjectival predication. Berlin: Mouton de Gruyter.

Young, Philip, and Talmy Givón. 1990. The puzzle of Ngäbére auxiliaries: Grammatical reconstruction in Chibchan and Misumalpan. In Studies in typology and diachrony: For Joseph H. Greenberg, ed. William Croft, Keith Denning, and Suzanne Kemmer, 207-243. Amsterdam: John Benjamins. 